
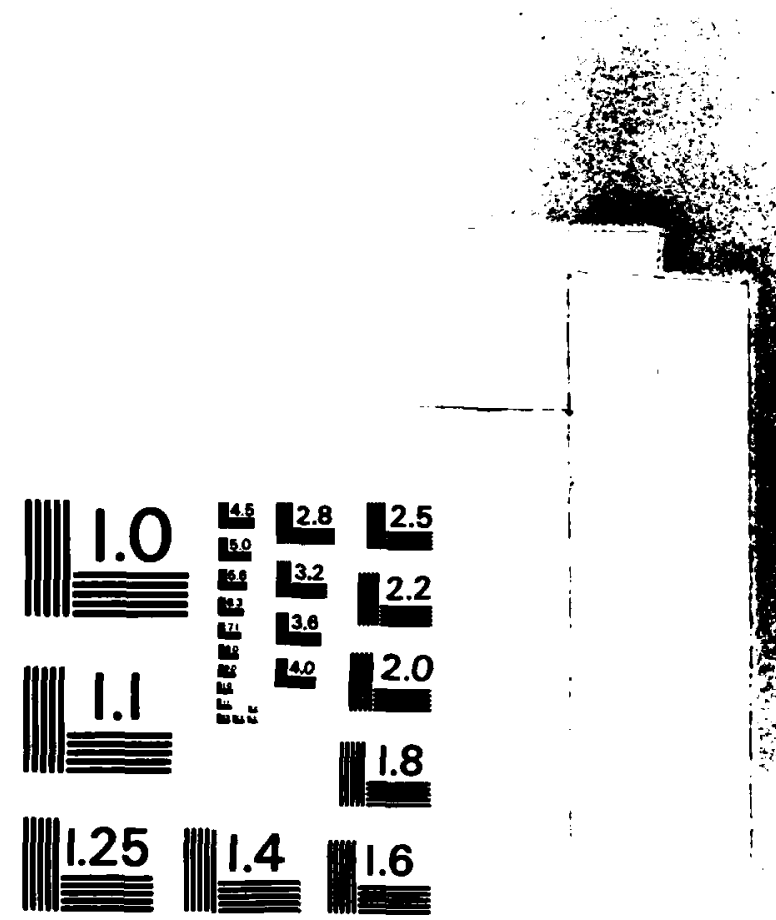

2.0 
This report is the final report on research carried out under $U$. $S$. Air Force Grant No. AFOSR 81-0046. The period covered is from 1 December 1980 until 30 November 1984, and the program was entitled "The Fatigue of Powder Metallurgy Alloys". Powder metallurgy alloys are attractive because their use can minimize material waste and minimize machining costs. In addition there is the potential for the development of more fine-grained and homogeneous microstructures as compared to ingot alloys, as well as the possibility for creating mechanically alloyed product which might not be producible via conventional ingot practice. However these attractive features are only of use if the mechanical properties are equivalent to, or hopefully better than, those of conventional ingot alloys. Fatigue behavior is one of the critical considerations in making such comparisons, particularly with respect to potential applications in the aero-space field. One main purpose of the research carried out in this program was to compare the fatigue crack propagation behavior of powder metallurgy $(P / M)$ alloys with comparable ingot metallurgy (I/M) alloys. In making these comparisons aluminum $P / M$ and $I / M$ alloys were used. Additional studies of titanium alloys were also carried out. This involved both low cycle fatigue as well as fatigue crack growth testing. As a result of this test program significant insight into the importance of crack closure on fatigue crack growth has been obtained. This insight leads to an improved understanding of the so-called anomolous growth of short cracks, fatigue notch sensitivity, notch size effects in fatigue, and overload effects assoclated with crack retardation. Crack closure provides a solfd physical basis for the quantitative modeling of these various phenomena. The specific details are provided in the following sections.

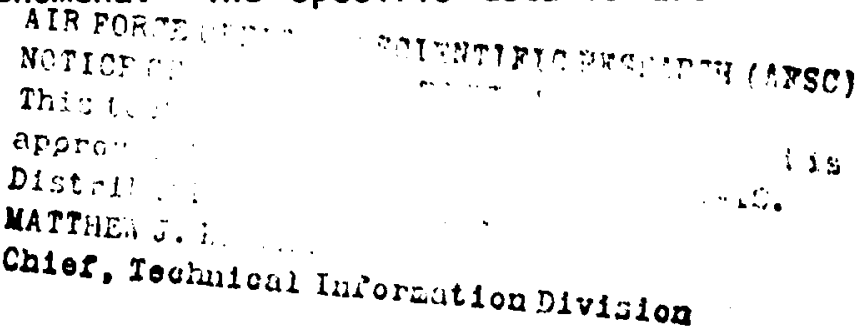




\section{MATERIALS AND TESTS}

Table 1 provides a complete listing of the alloys studied in this program together with their chemical compositions. Table 2 lists the mechanical properties of the alloys.

Fatigue crack growth studies were carried out using compact specimens. A subtraction circuit as indicated in Fig. I was used to determine the crack opening load. Both clip gages as well as back-face strain gages were employed in the course of the program in the determination of the crack opening load level. Since the signal output from the back-face gage is cleaner and the sensitivity is similar to that of the clip gage, we prefer the use of the back-face strain gage.

Much of the fatigue crack growth work was carried out in air at room temperature. In the threshold region frequencies of up to 50 Hertz were used. Some additional testing was carried out in $31 / 2 \% \mathrm{NaCl}$ solution to determine the effect of this environment on the rate of crack growth. The low cycle fatigue work on titanium alloys was carried out at elevated temperatures in air or in a partial vacuum with the specimen heated by induction.

\section{TEST RESULTS - ALUMINUM ALLOYS}

Fig. 2 shows the resuits of fatigue tests carried out under fully reversed loading conditions in the high cycle range with smooth specimens. $X 7090$ and $X 7091$ are $P / M$ alloys, 7075 is an ingot alloy. The fatigue properties of the $P / M$ alloys are better than those of the $I / M$ alloy, an indication that these $P / M$ alloys do not contain significant defects such as porosity which would degrade the fatigue performance.

Figs. 3 and 4 show typical results of fatigue crack growth analyses for $P / M$ and $I / M$ alloys. A comparison is provided in Fig. 5. Test varlables 


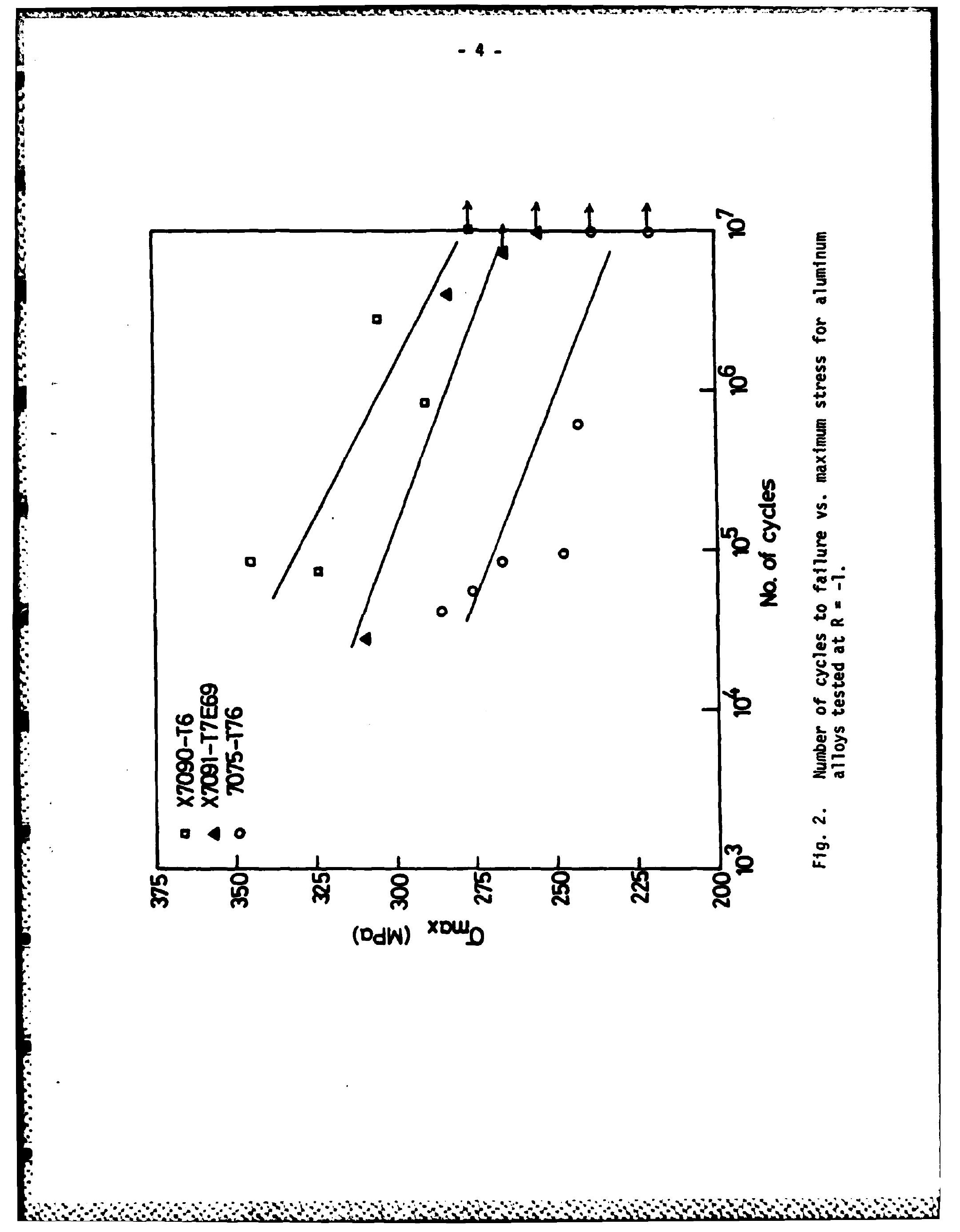




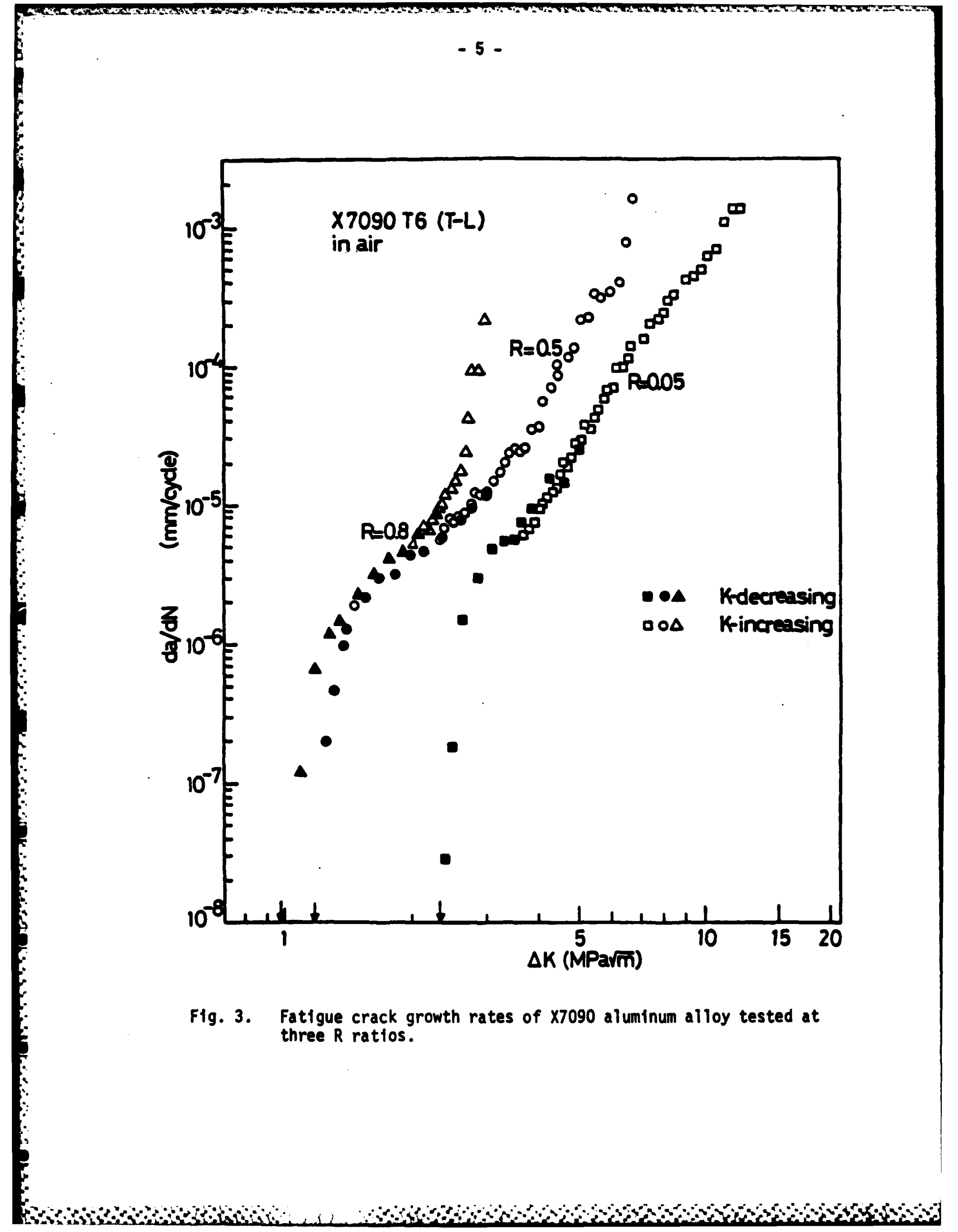


included the R-ratio (the ratio of minimum to maximum stress in a cycle) and the orientation of the specimen with respect to the rolling direction of the plate from which the specimens were machines. Both K-decreasing and $k$-increasing test procedures were used to check on repeatablity and to insure that load history effects were minimal. From Fig. 5 it can be seen that at threshold the $P / M$ alloys are actually better than the comparable I/M alloy, but in the intermediate crack growth region the reverse is true. These results will be discussed in terms of crack closure subsequently.

The dependence of the crack growth rate on $R$ is indicated in Fig. 6 for the P/M alloys.

The crack closure behavior in terms of the ratio of Kop/Kmax is shown in Fig. 7 for both $P / M$ and $I / M$ materials for an R-ratio of 0.05 . The influence of R-ratio on closure behavior is shown in Fig. 8. It is noted that the closure effect increases as threshold is approached and also that the effect decreases with increase in R-ratio. $\Delta$ Keff is the portion of the cycle in which the crack tip is open. The crack growth rates plotted in terms of this parameter are shown in Fig. 9. Much of the dependency of the crack growth rate on $R$ can be accounted for on the basis of crack closure. The difference at threshold is in fact quite small in the absolute sense. The differences apparent at the highest growth rates are real and are due to the fact that the peak value of $K$ is much higher for a high R-ratio at a given $\Delta K$ and this gives rise to additional modes of separation because of the proximity to the fracture toughness level. It is also noted that the earlier comparison between P/M and I/M alloys, Fig. 5, can be accounted for in terms of the closure effect. At threshold it was less for the I/M alloy but in the intermediate range it was higher.

Fig. 10 shows the crack growth behavior as a function of $R$ for a mechanically alloyed $P / M$ alloy. Note the absence of an $R$ effect in the low 


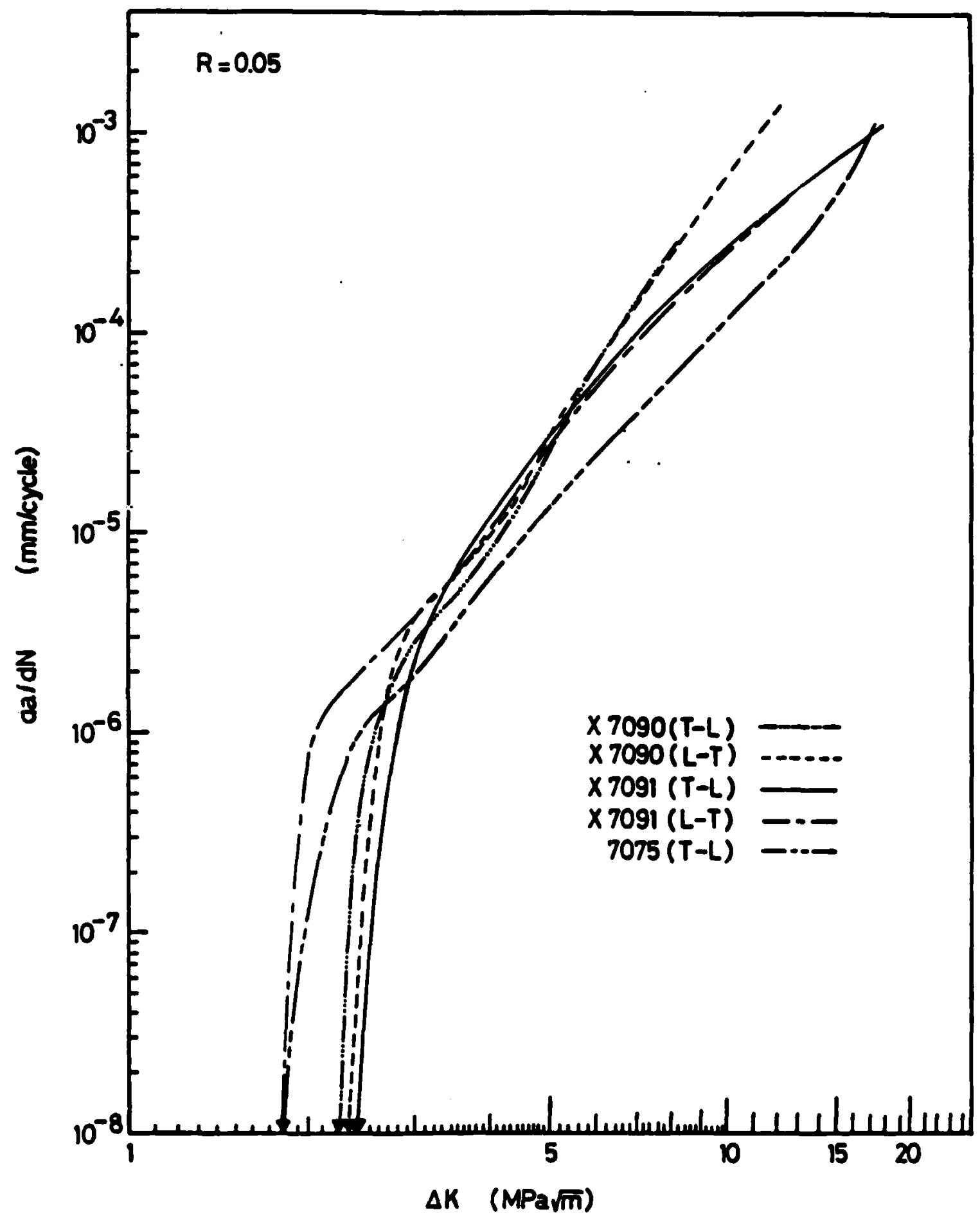

Fig. 5. Fatigue crack growth rates as a function of $\Delta K$ for $P / M$ and $I / M$ alloys $(R=0.05)$. 


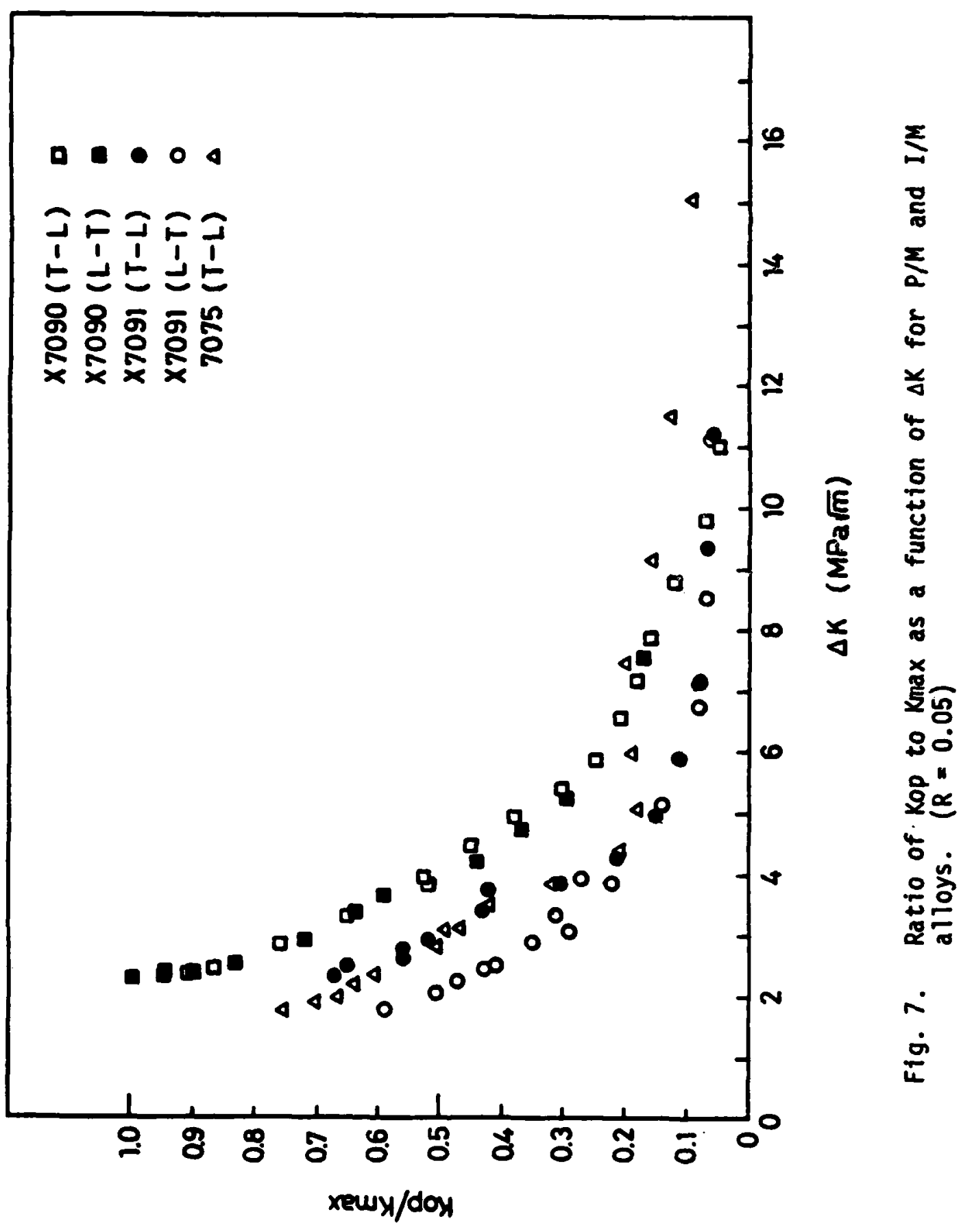




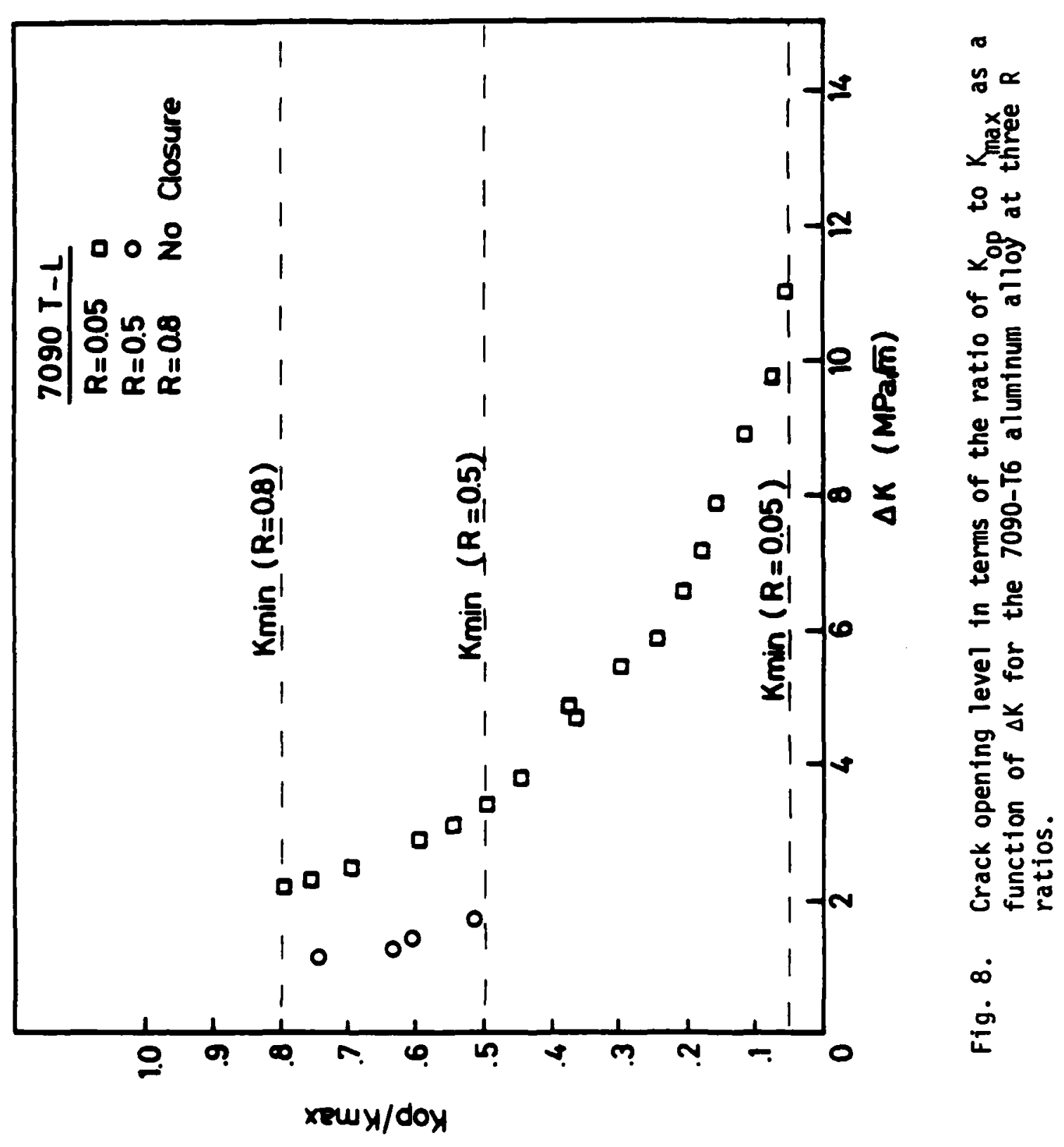




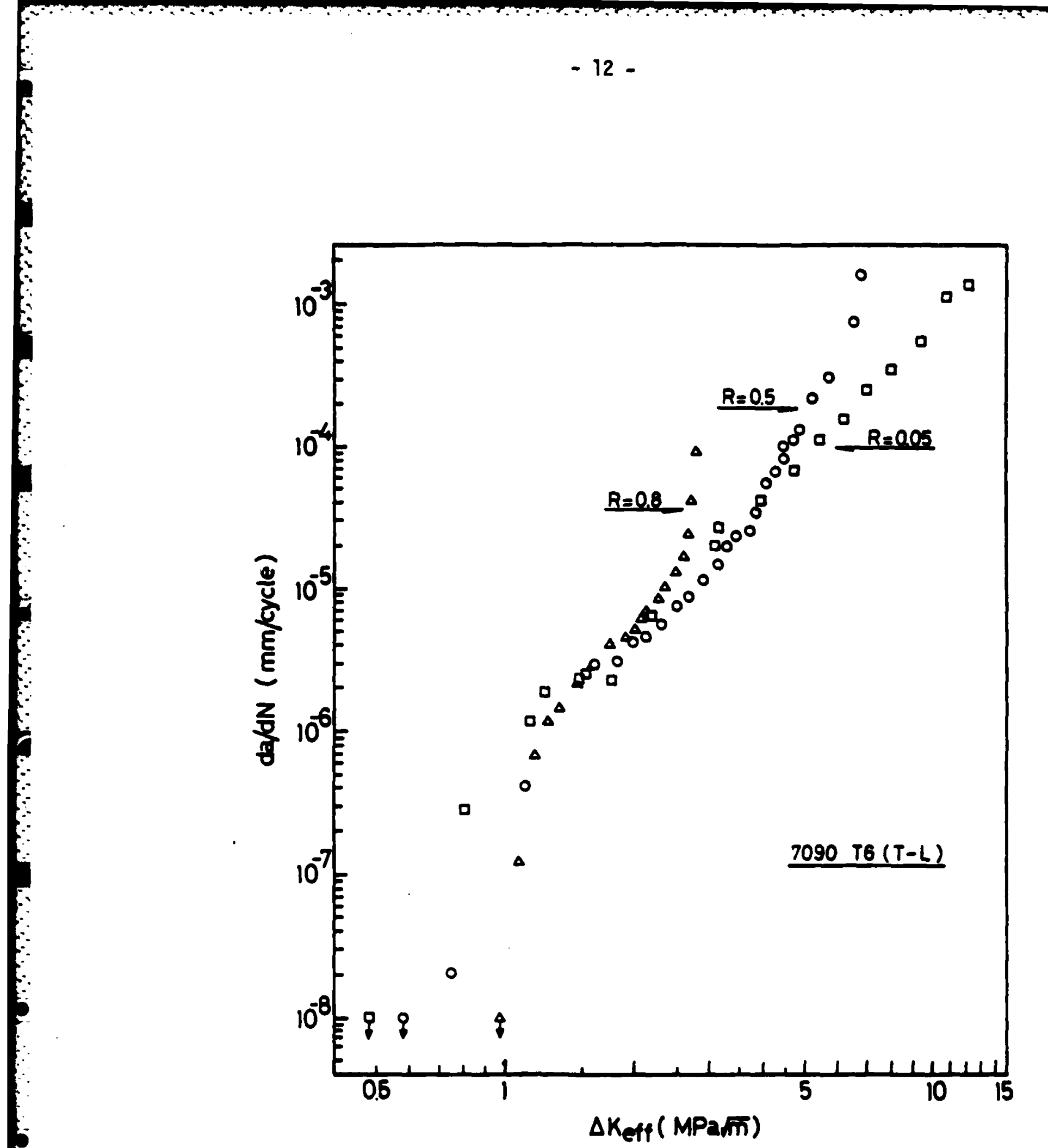

Fig. 9. Fatigue crack growth rate, da/dN, as a function of $\Delta K_{\text {eff }}$ for
the $7090-T 6$ alloy. 


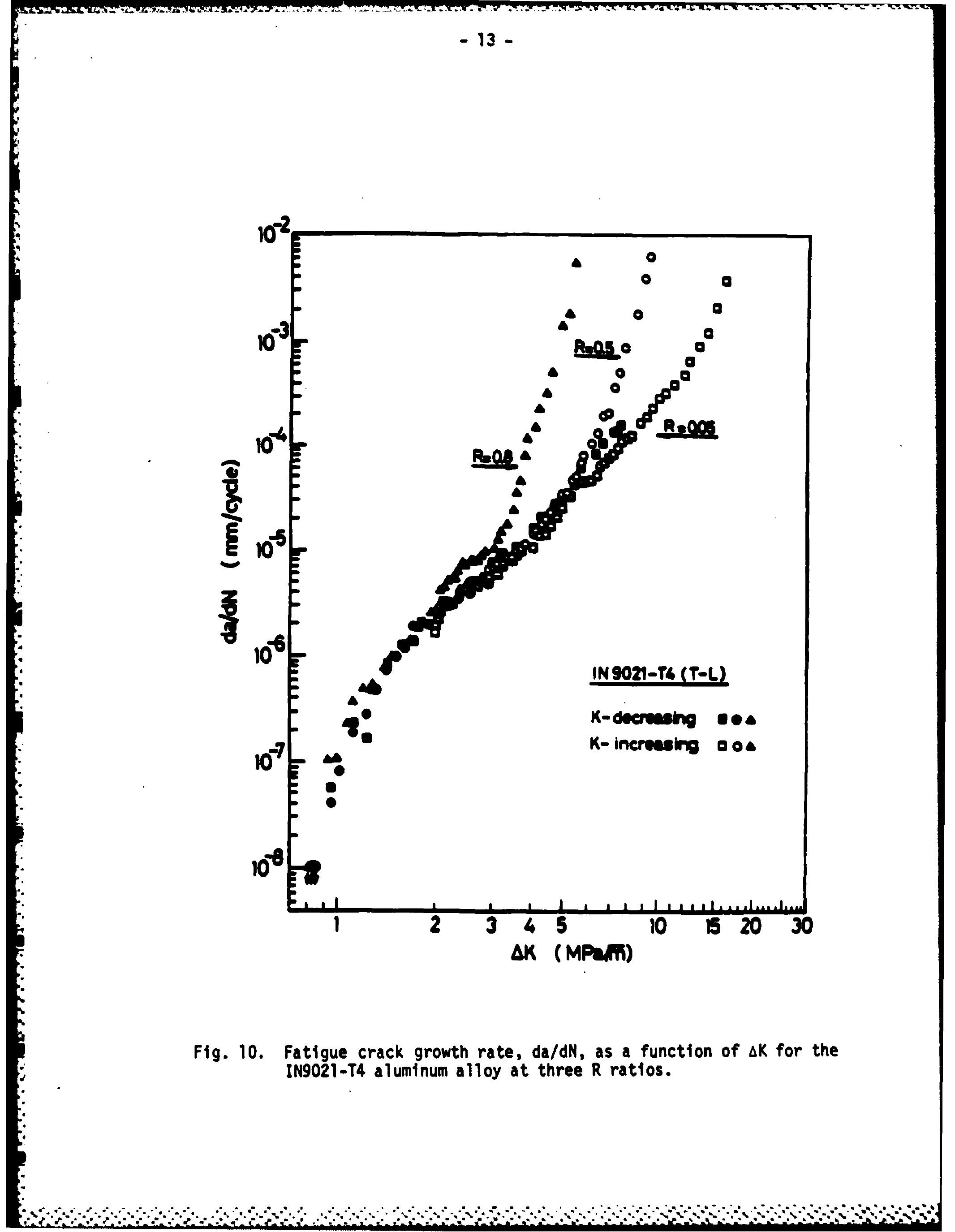


rate region. This alloy is extremely fine-grained, less than a micron, and exhibited no crack closure. This result provides clear cut evidence that the $R$ effect on the level of the threshold is due to closure. Fig. 11 emphasizes this point. Where there is no closure there is no $R$ effect as in the case of IN9021. In the more usual case closure is high at low $R$ ratios and decreases with increase in $R$ with the result that the threshold level also decreases with $R$ as in the case of the $7090 \mathrm{P} / \mathrm{M}$ alloy. These results are plotted in a different manner in Figs. 12 and 13 . It is interesting to note that in the case of the 7090 alloy that the value of $K \max$ is fairly constant for low values of $R$.

Figs. 14 through 17 show the effect of a simulated sea water environment on the rate of fatfgue crack propagation in $7 x x x$ alloys. In general there is a degradation in resistance to fatigue crack growth in the salt water. However the I/M alloy actually had a slightly higher threshold in the salt water as compared to air. For this alloy closure was higher in the salt water than in air as shown in Fig. 18. This effect may be due to corrosion product wedging. The closure results for the other alloys are shown in Figs. 19-21, and a comparison between the alloys is given in Fig. 22. Just why the closure is higher in the case of the ingot alloy has not been determined. At any rate nothing has emerged from these tests, either in air or salt water environments, which would suggest that the $P / M$ alloys are in any way less than comparable to the corresponding ingot alloy.

\section{TEST RESULTS - TITANIUM ALLOYS}

In the course of the program $S / N$ curves for the titanium alloy TI-6AT-4V were obtained in both the as-recefved condition and in a cold rolled condition. The results were somewhat surprising, for as shown in Fig. 23, cold rolling has lead to a degradation in fatigue properties. Generally speaking 


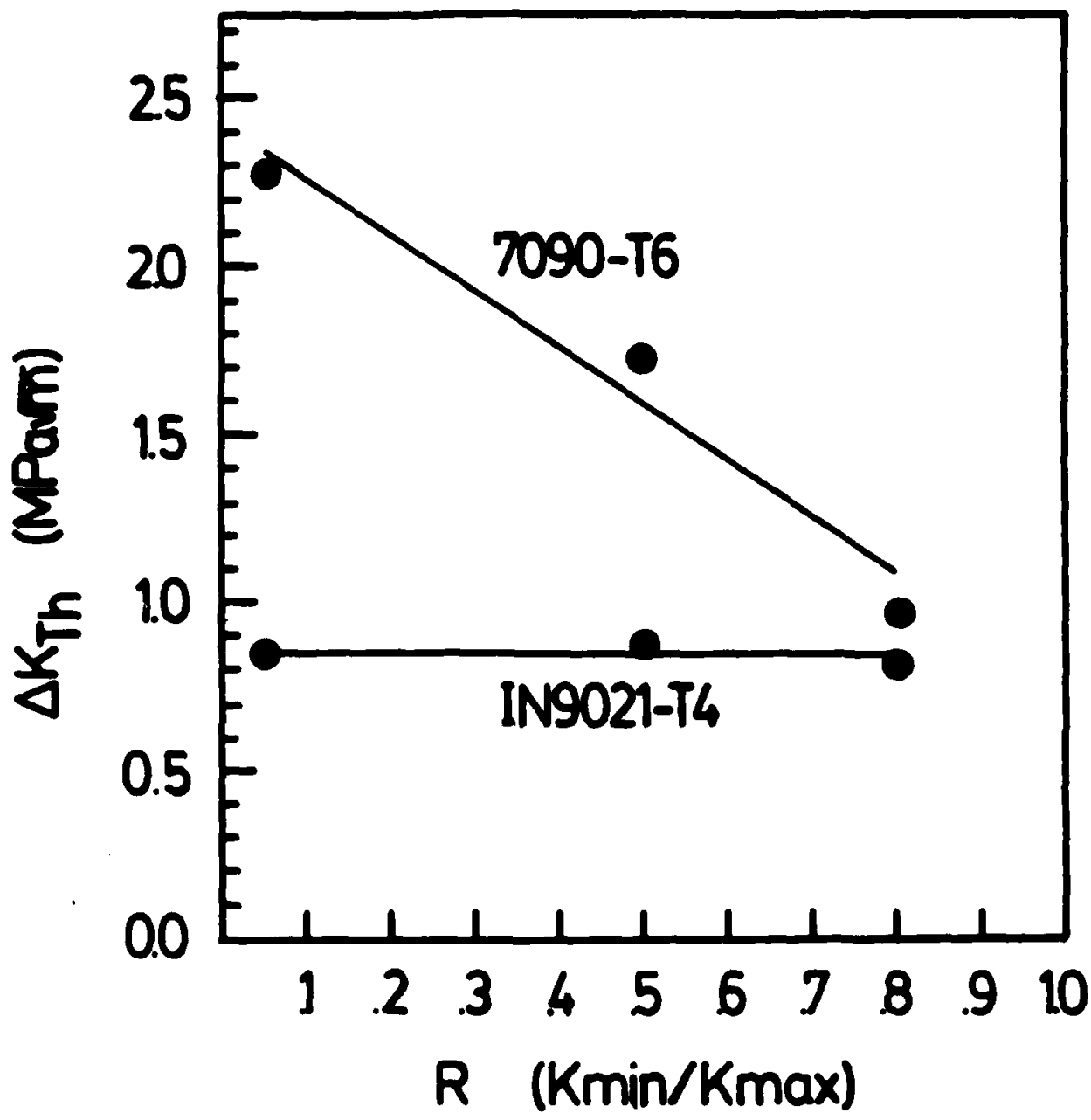

Fig. 11. Comparison of fatigue threshold levels for the IN9021 and 7090 alloys at three $R$ ratios. 


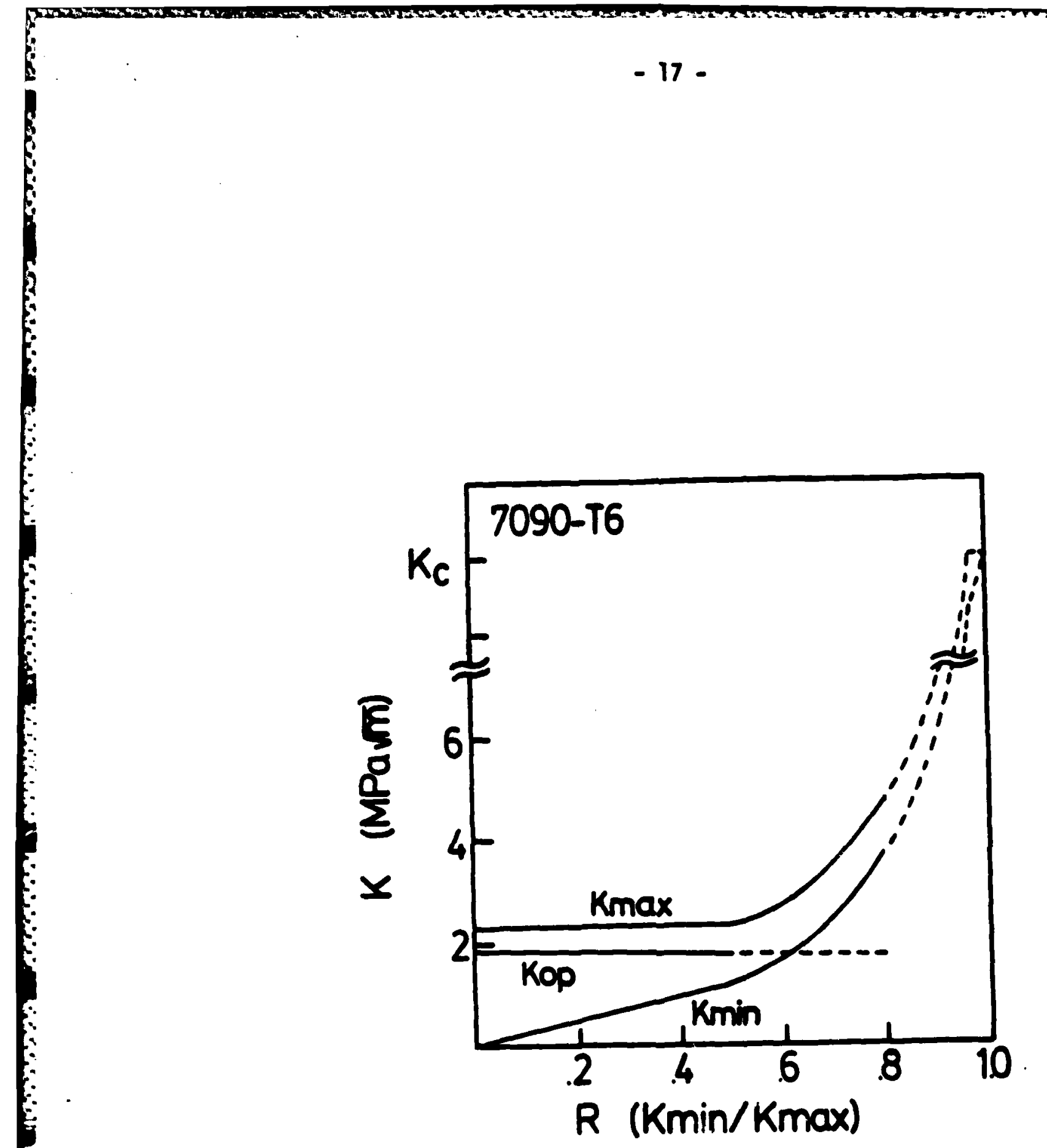

Fig. 13. $K_{\max }, K_{\min }$ and $K_{o p}$ as a function of $R$ for the 7090-T6 alloy. 


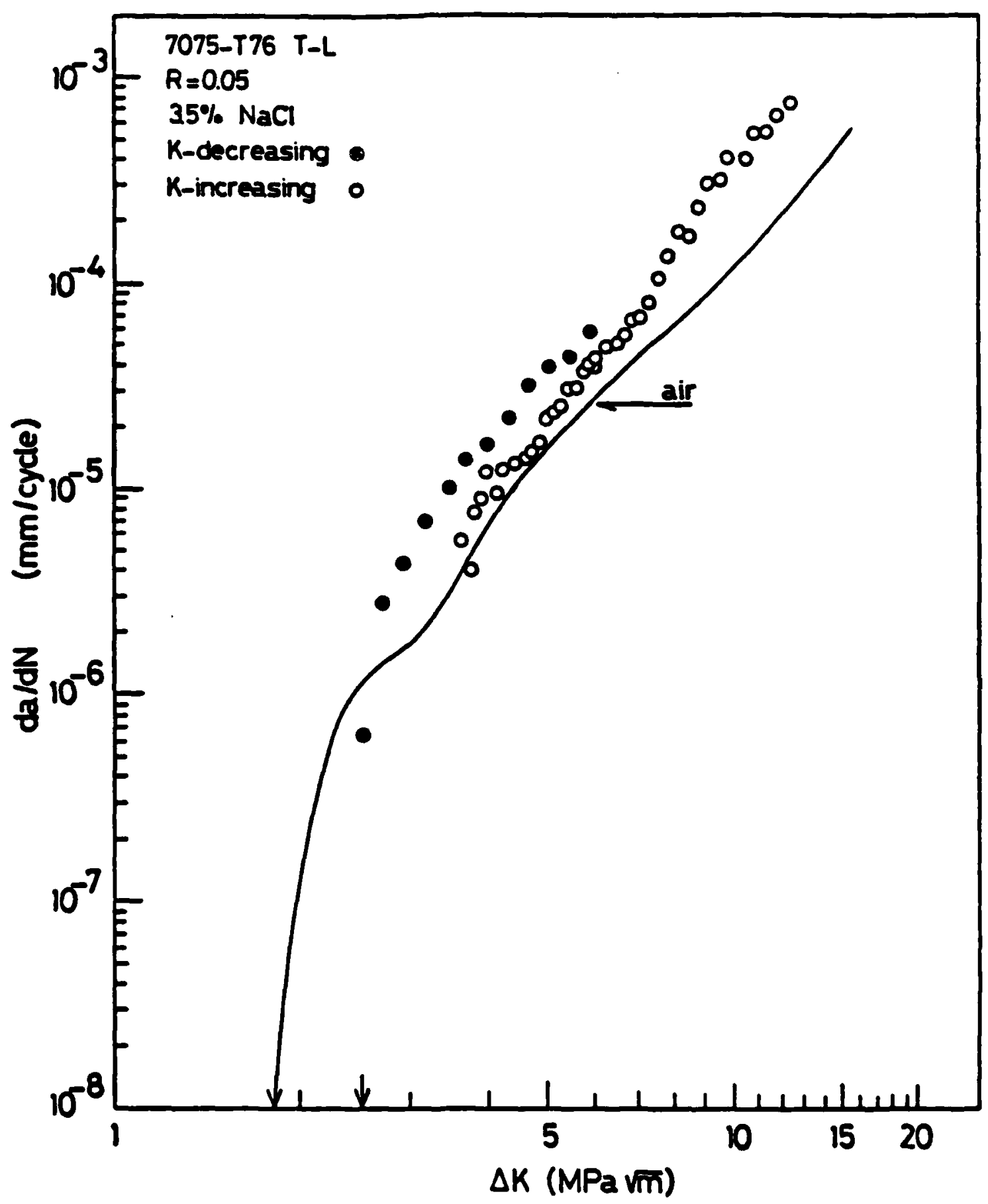

Fig. 14. Fatigue crack growth rates of 7075 aluminum alloy tested at $R=0.05$ in 3.5 pct. $\mathrm{NaCl}$ solution. 


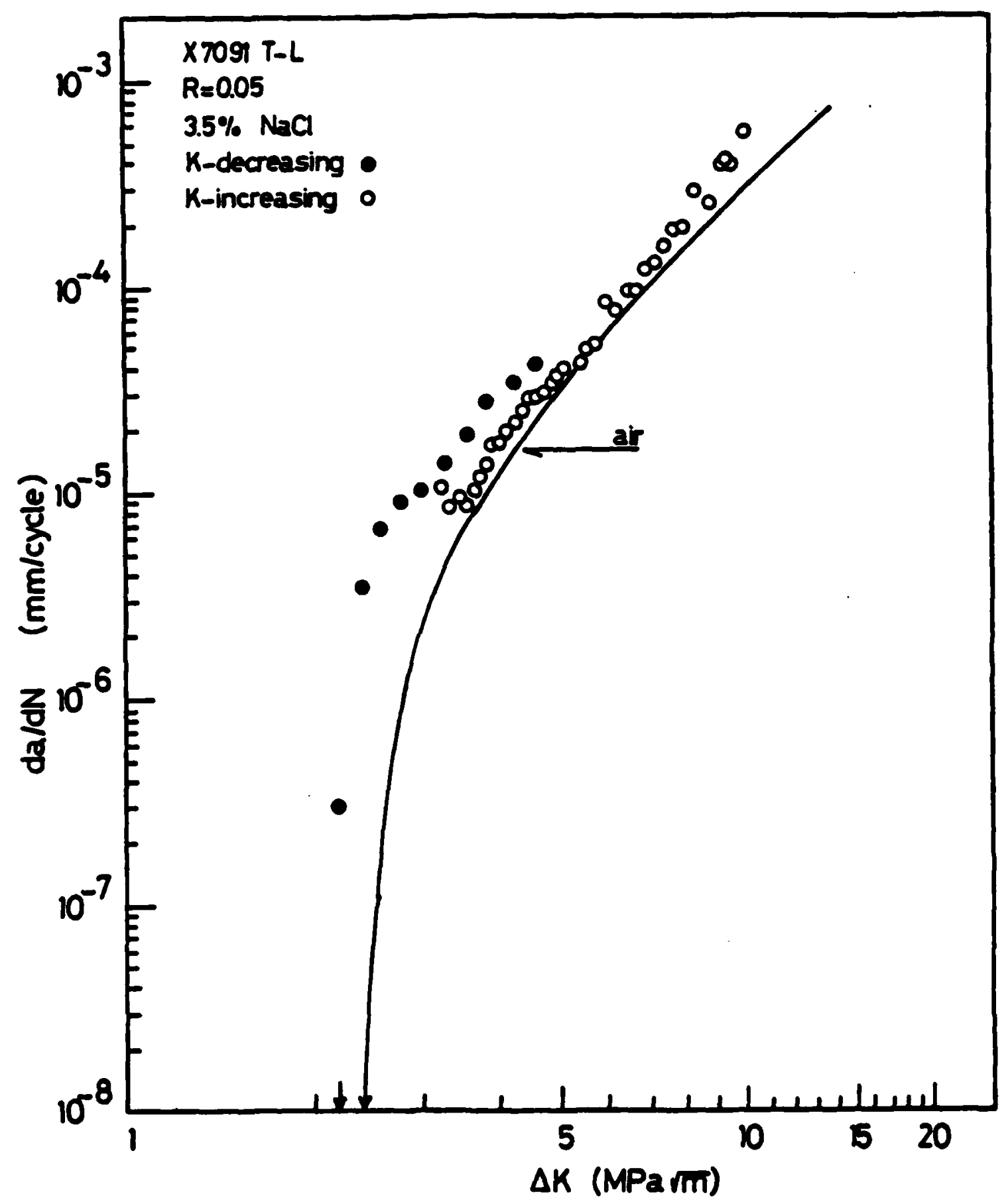

Fig. 15. Fatigue crack growth rates of $X 7091$ aluminum alloy tested at $R=0.05$ in 3.5 pct. NaCl solution. 


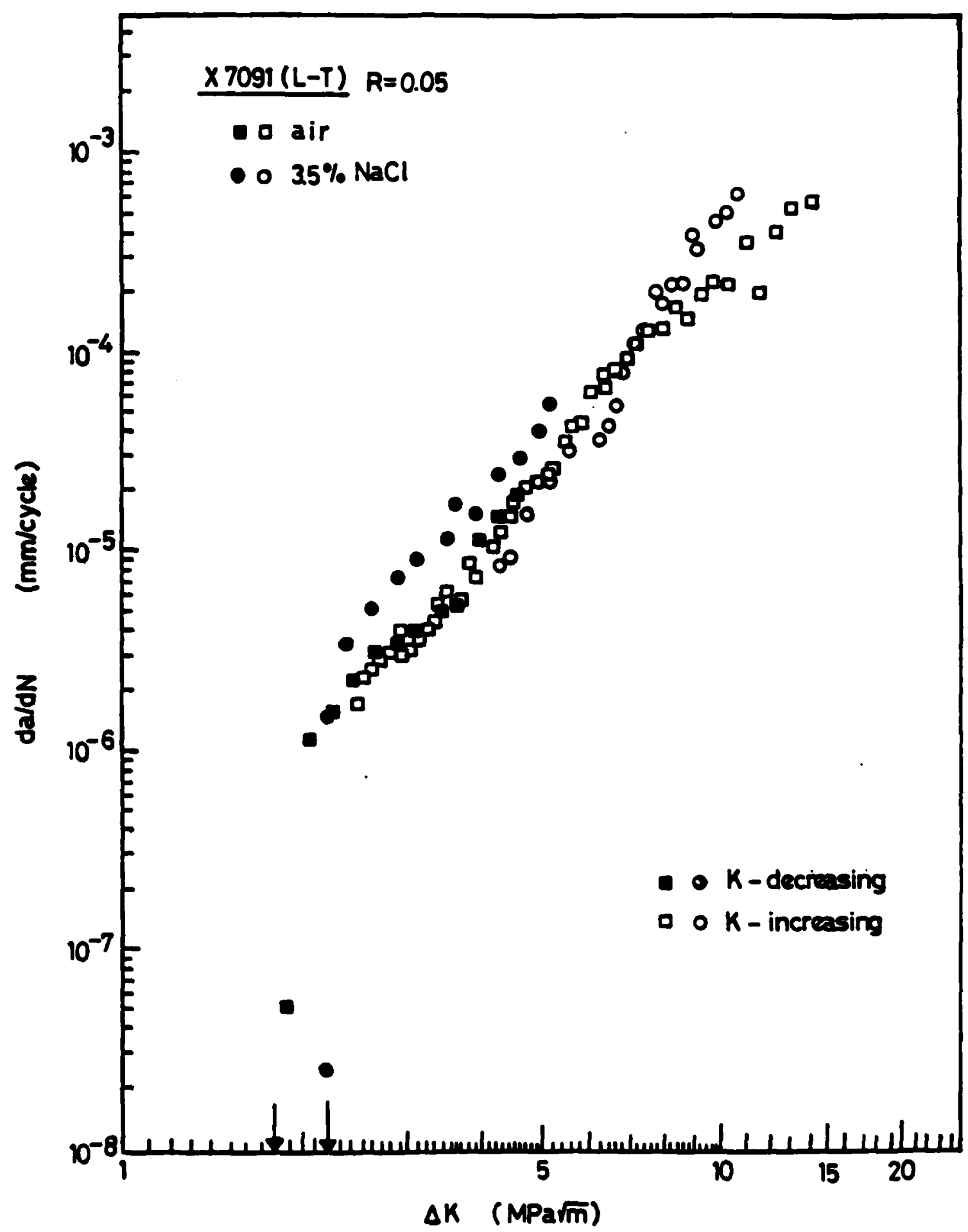

F1g. 16. Rate of fatigue crack growth in $3.5 \% \mathrm{NaCl}$ for $X 7091$ (L-T) compared to growth rate in air under decreasing and increasing $K$ conditions. 


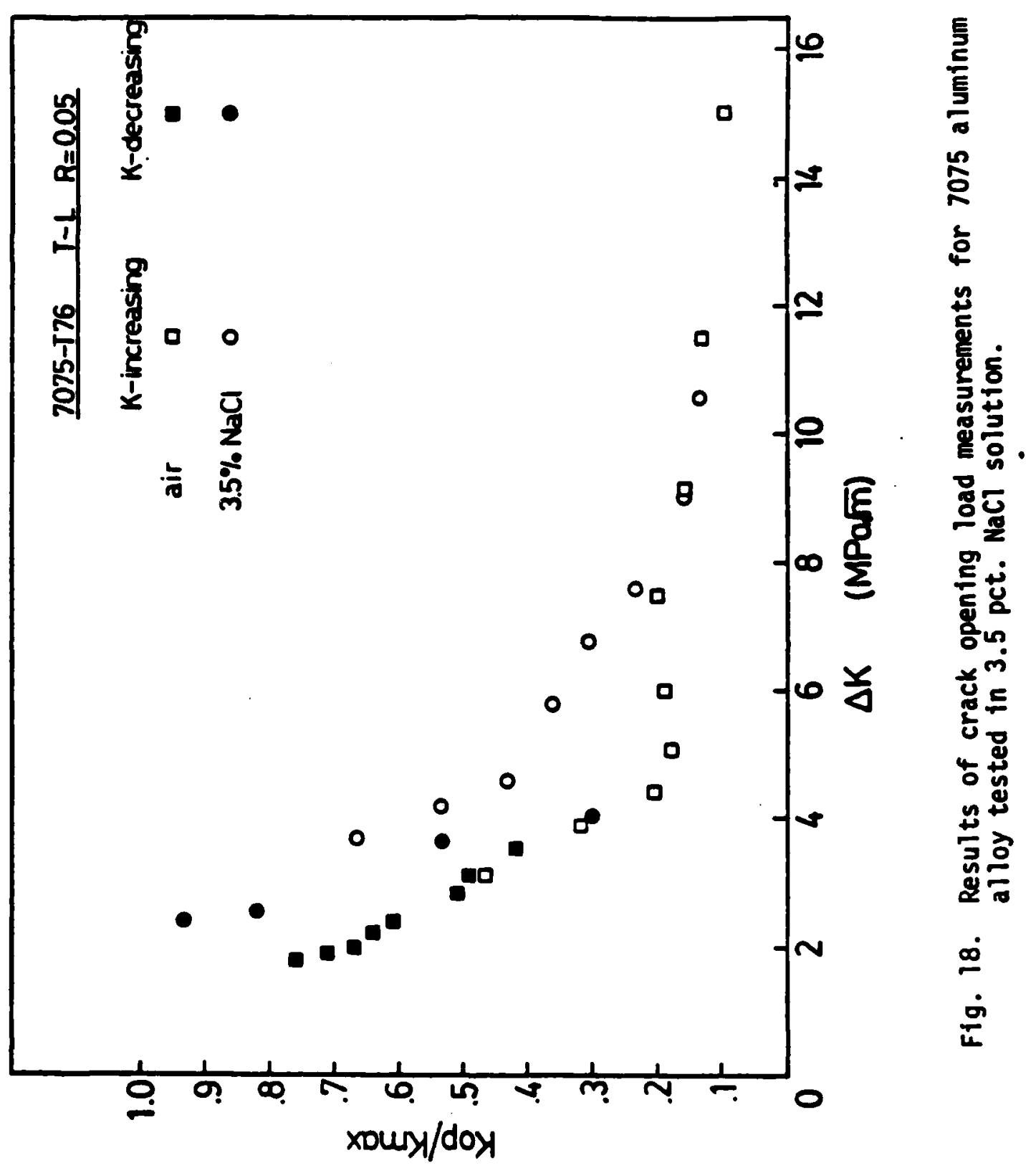




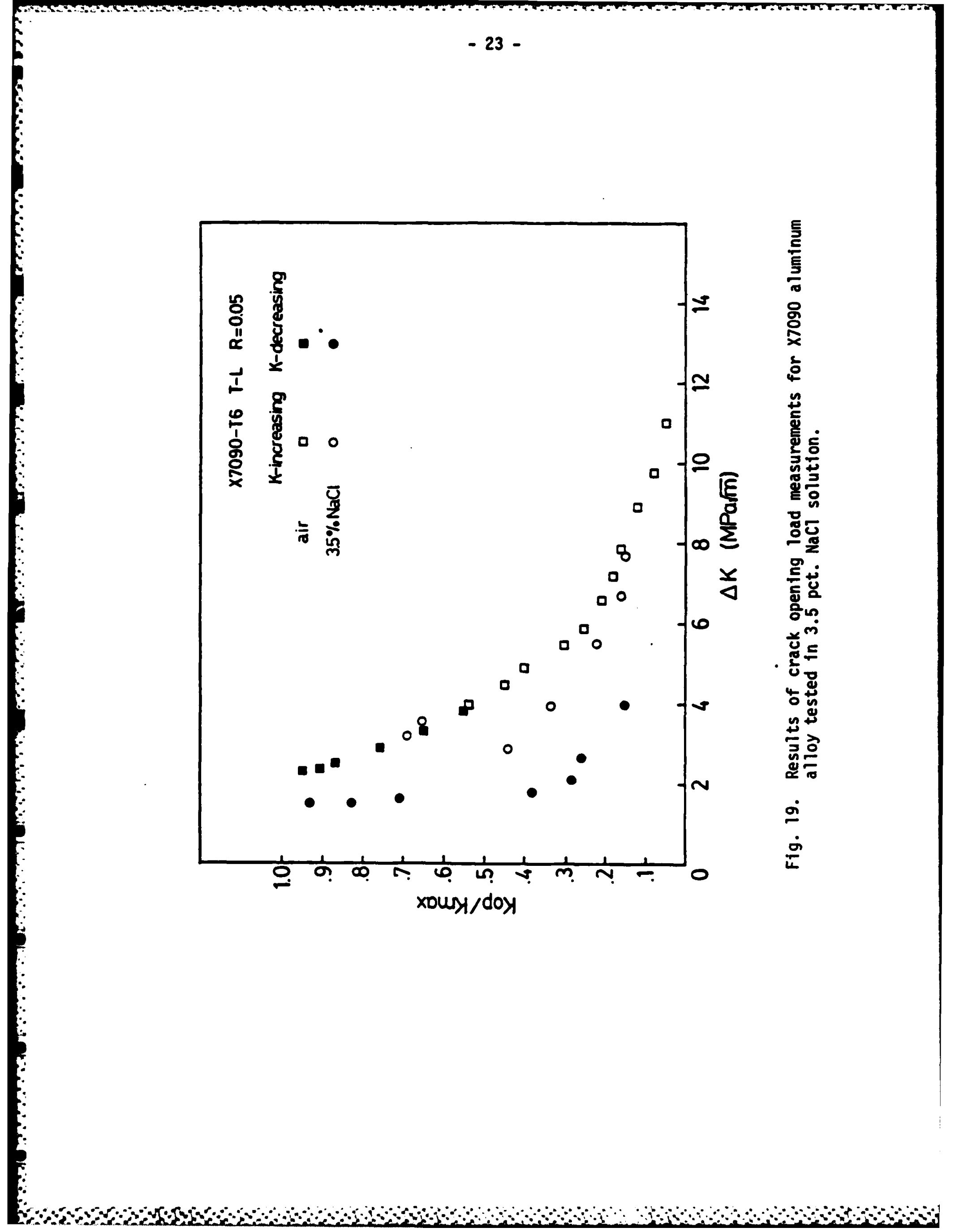




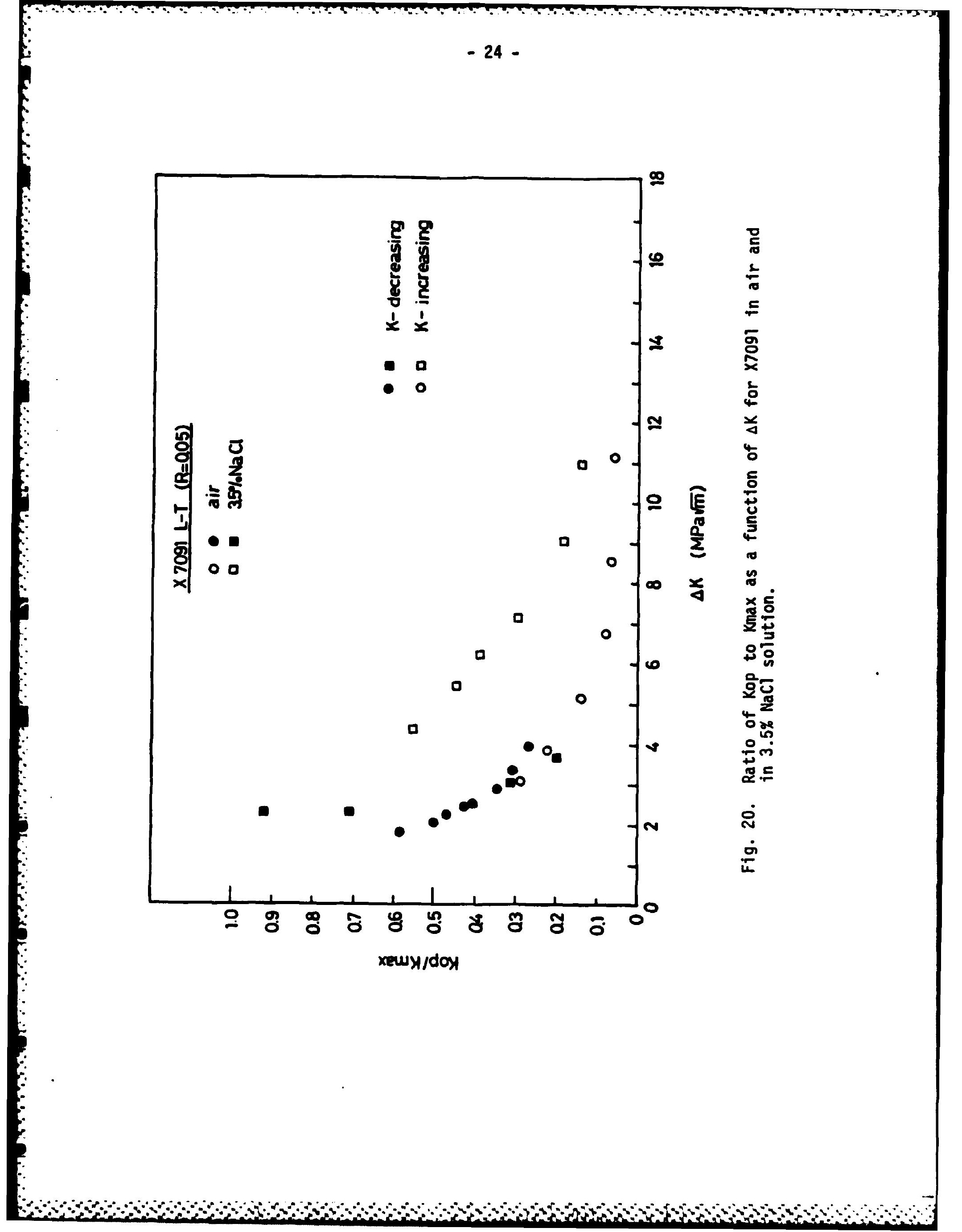




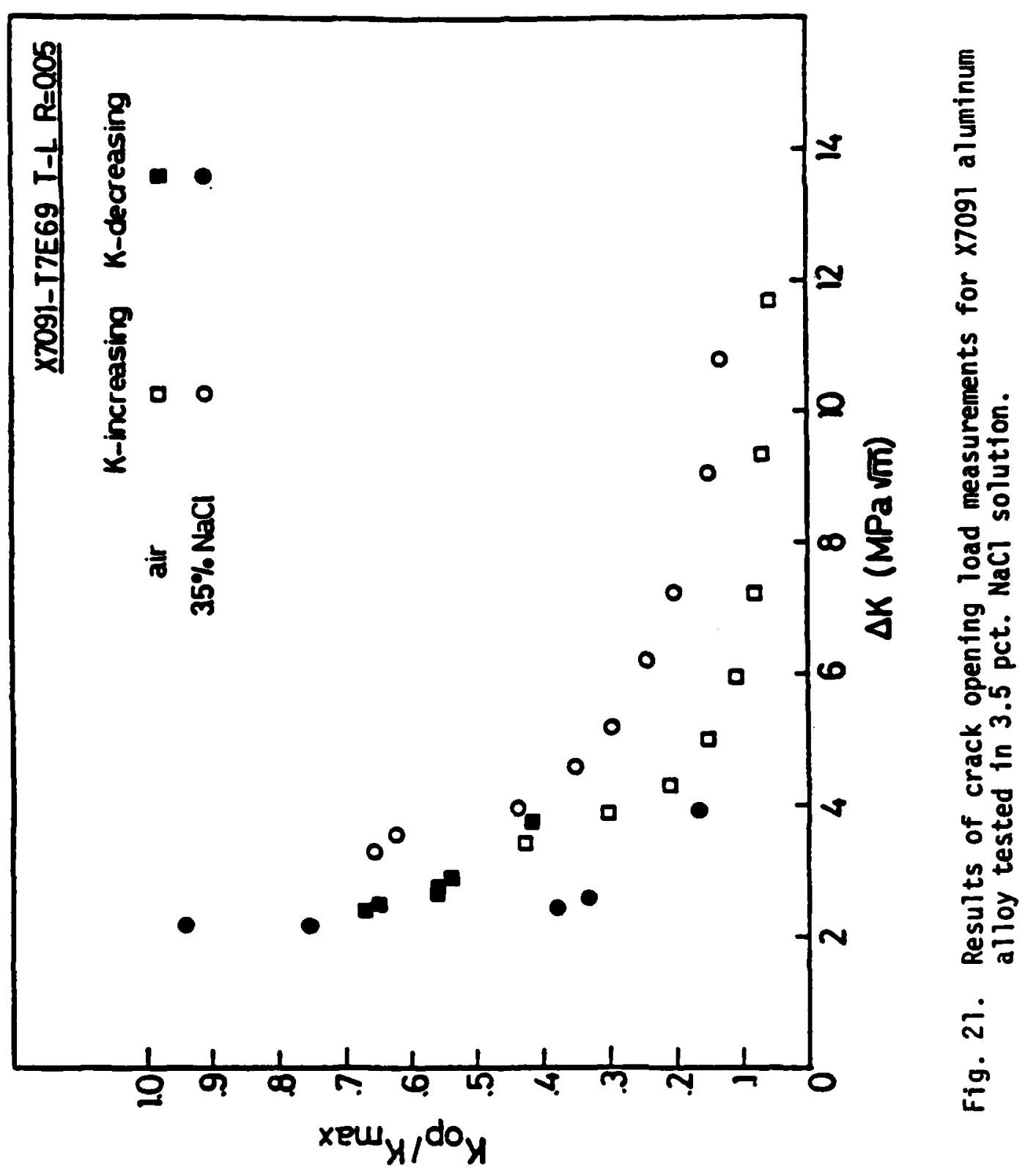




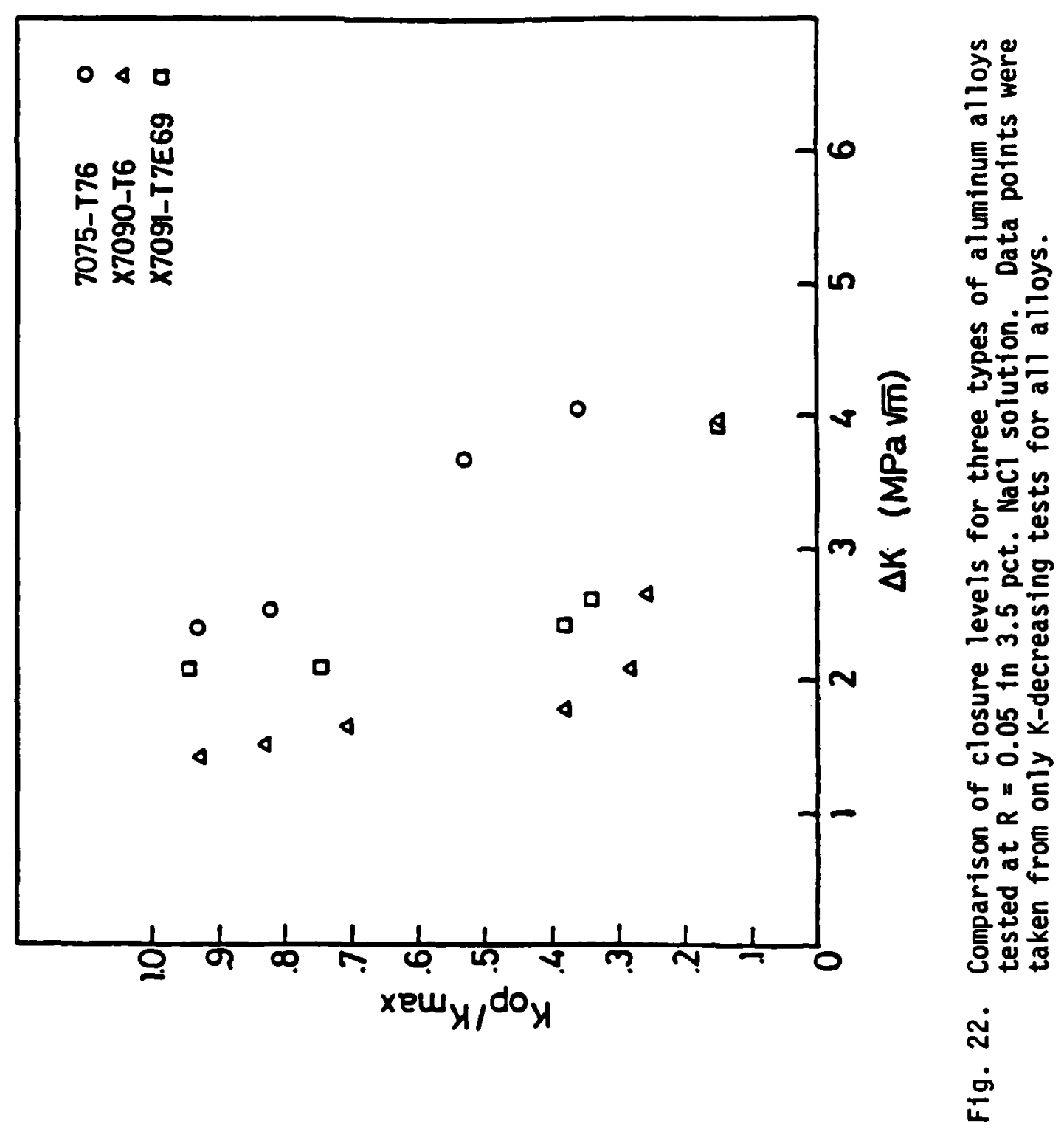




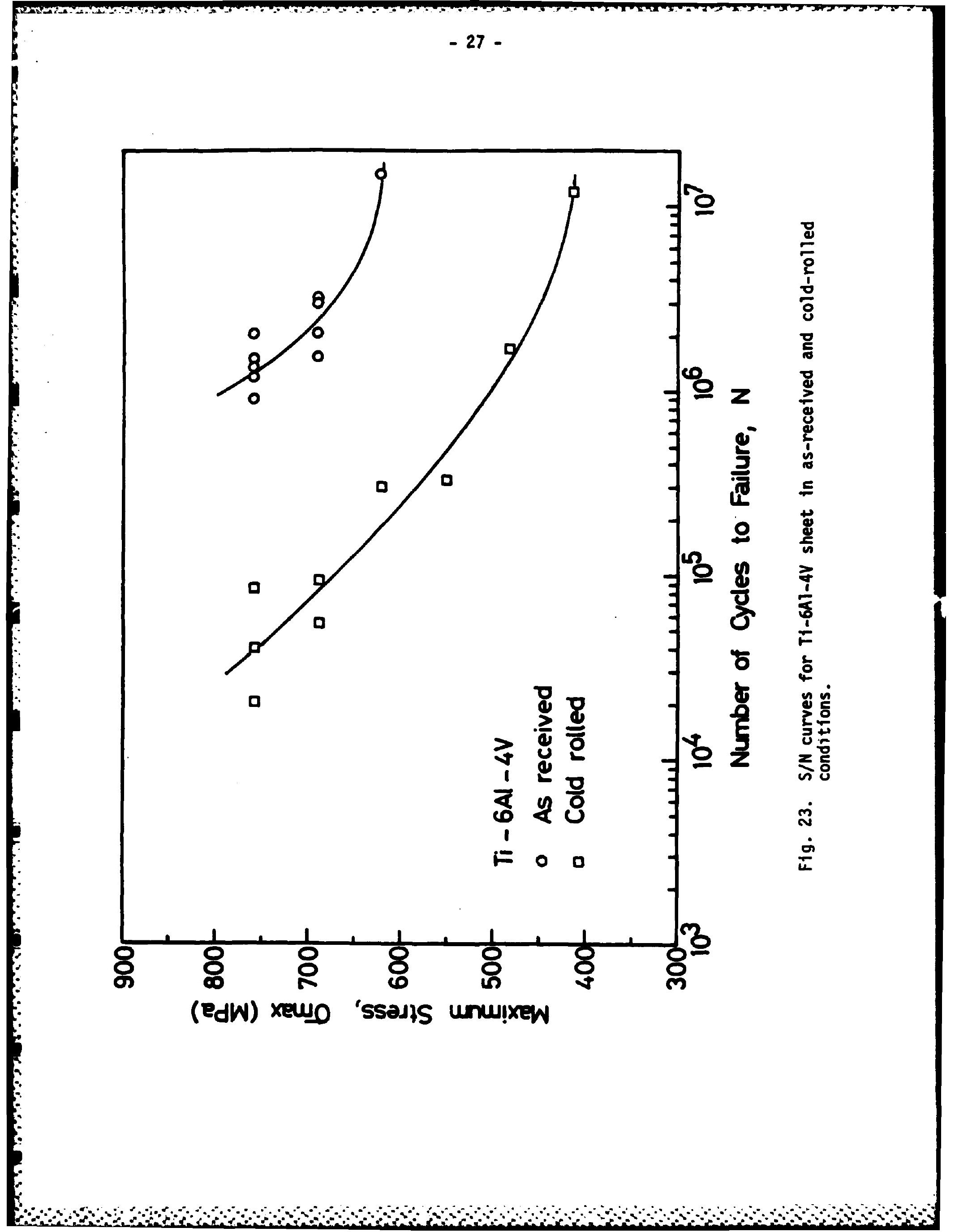


the opposite effect would have been observed. This result appears to correlate with the unique microstructure of the alpha-beta titanium alloy. The beta phase acts as a strengthener for the alpha phase. But when it is sheared as in the course of cold rolling, this strengthening effect is greatly reduced and locally the plastic deformation required for fatigue crack initiation can proceed more readily, thus accounting for the observed degradation in fatigue resistance.

We have also obtained some additional crack growth data for the titanium alloy 5524S which was tested in a joint French-American program some time earlier. In reviewing the results of that program there was a question about the validity of test results in the low $\Delta K$ regime. Our results confirmed the results obtained by the French investigators but also indicated that the threshold at $450 \mathrm{C}$ was quite low as indicated in Fig. 24 . Fig. 25 shows that the closure level is low in this alloy and fairly constant down to the threshold level. At threshold the ratio of Kop to Kmax is of the order of 0.25 whereas at room temperature a ratio of the order of 0.5 would be obtained. A common characteristic of all alloys is the loss of closure with increase in temperature as the result of the easier flattening of contacting points with increase in temperature.

Low cycle fatigue tests have also been carried out at $525 \mathrm{C}$ on the titanium alloy IMI 829 in air and in a partial vacuum. This alloy was available in both $I / M$ and $P / M$ forms so that a direct comparison could be made to determine if there was an influence of processing history on fatigue behavior. The results of the tests are shown in Fig. 26 for two different frequencies of test as a function of the total strain range. Little difference between $P / M$ and $I / M$ specimens is found in air testing. In vacuum the $P / M$ alloy seems better, and there is an increase in fatigue iffe with frequency for the I/M material. However difficulties with leaks 


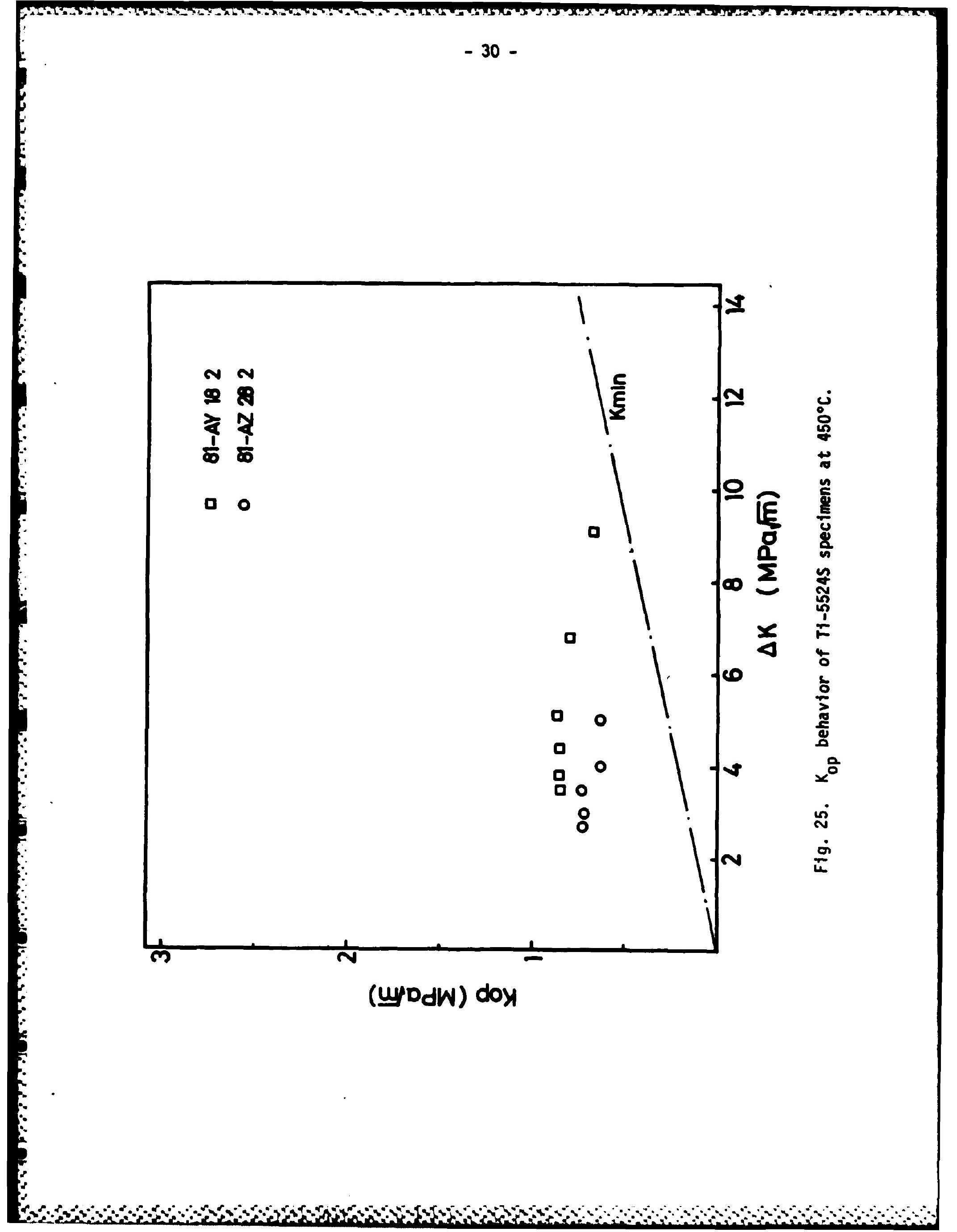


in the vacuum system may have influenced these results. Fig. 26 also presents the results as a function of the plastic strain range, and Fig. 27 and 28 compares the results for the IMI829 alloy with results previously obtained for two other candidate titanium alloys for high temperature applications. These results indicate that the IMI alloy is less resistant to low cycle fatigue than the other two alloys. However more testing should be done to confirm this finding and to establish the cause for the difference if one indeed exists.

ANALYSIS

As indicated in the previous section crack closure can provide an explanation for the dependency of the crack growth rate on mean stress in the near-threshold region. Since crack closure is also important in understanding other aspects of fatigue crack growth it is essential that we learn more of the nature of the closure process itself. When crack closure was first introduced by Elber it was related to a residual plastic stretch of material in the wake of a growing fatigue crack. This still seems to be an appropriate explanation in the case of plane stress. However under plane strain conditions as in the case of most threshold testing this does not provide an explanation for the development of closure. Instead we find that because of a shift from mode I to mode II crack growth as the stress intensity factor is reduced the fracture surface can become faceted. This extent of this faceting depends on the microstructure, for if the microstructure is extremely fine as in the case of the IN9021 alloy, then closure may not develop even in the threshold region. Microstructures which develop facets of the order of 10 microns or larger can lead to enhanced closure in the near-threshold region. Closure results due to a mismatch of these facets when the opposite sides of the crack attempt to close. This type of 


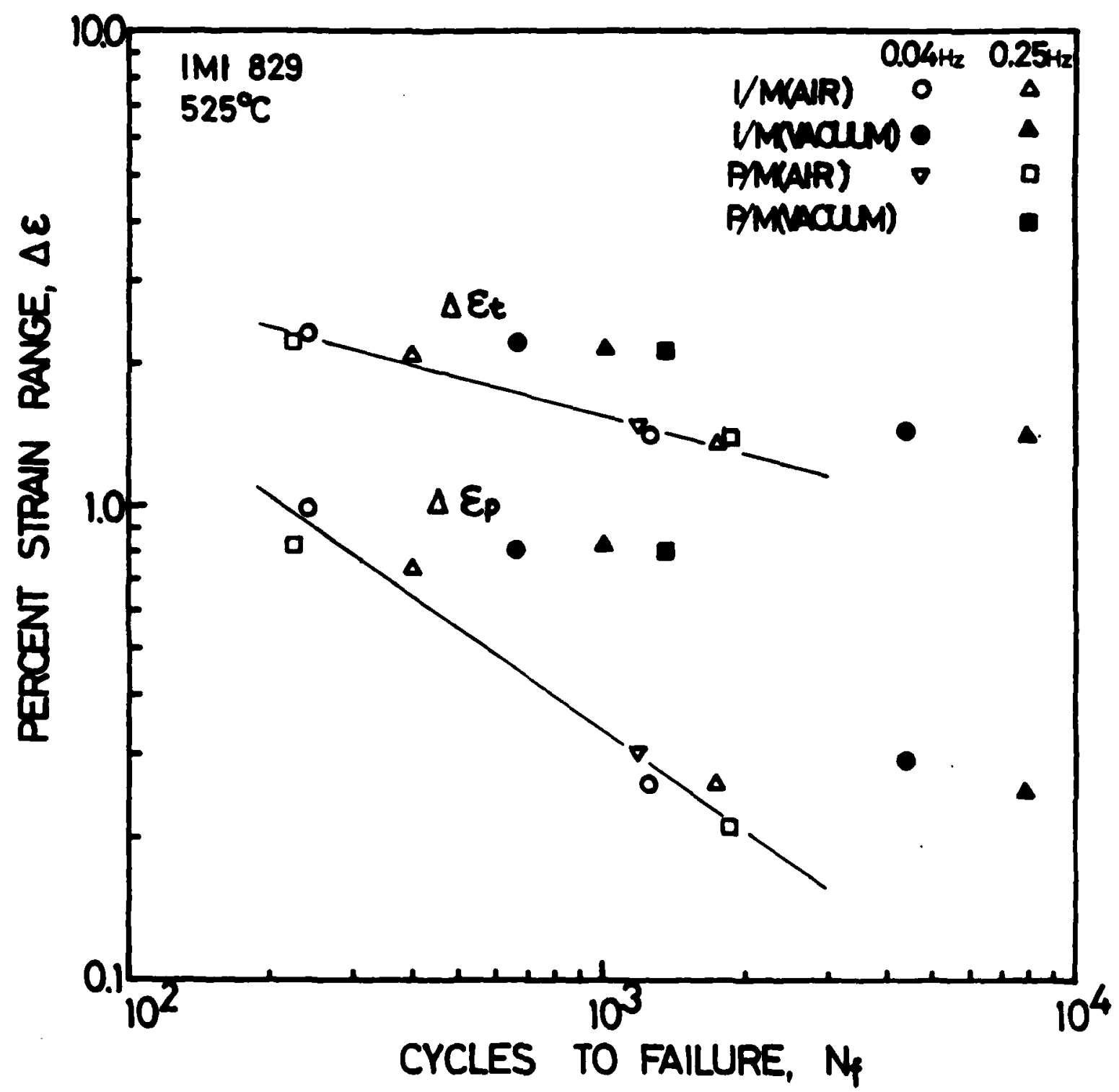

Fig. 26. Low Cycle Fatigue behavior of IMI 829 at $525^{\circ} \mathrm{C}$ in terms of total strain range and the plastic strain range. $P / M$ and $I / M$ alloys. 


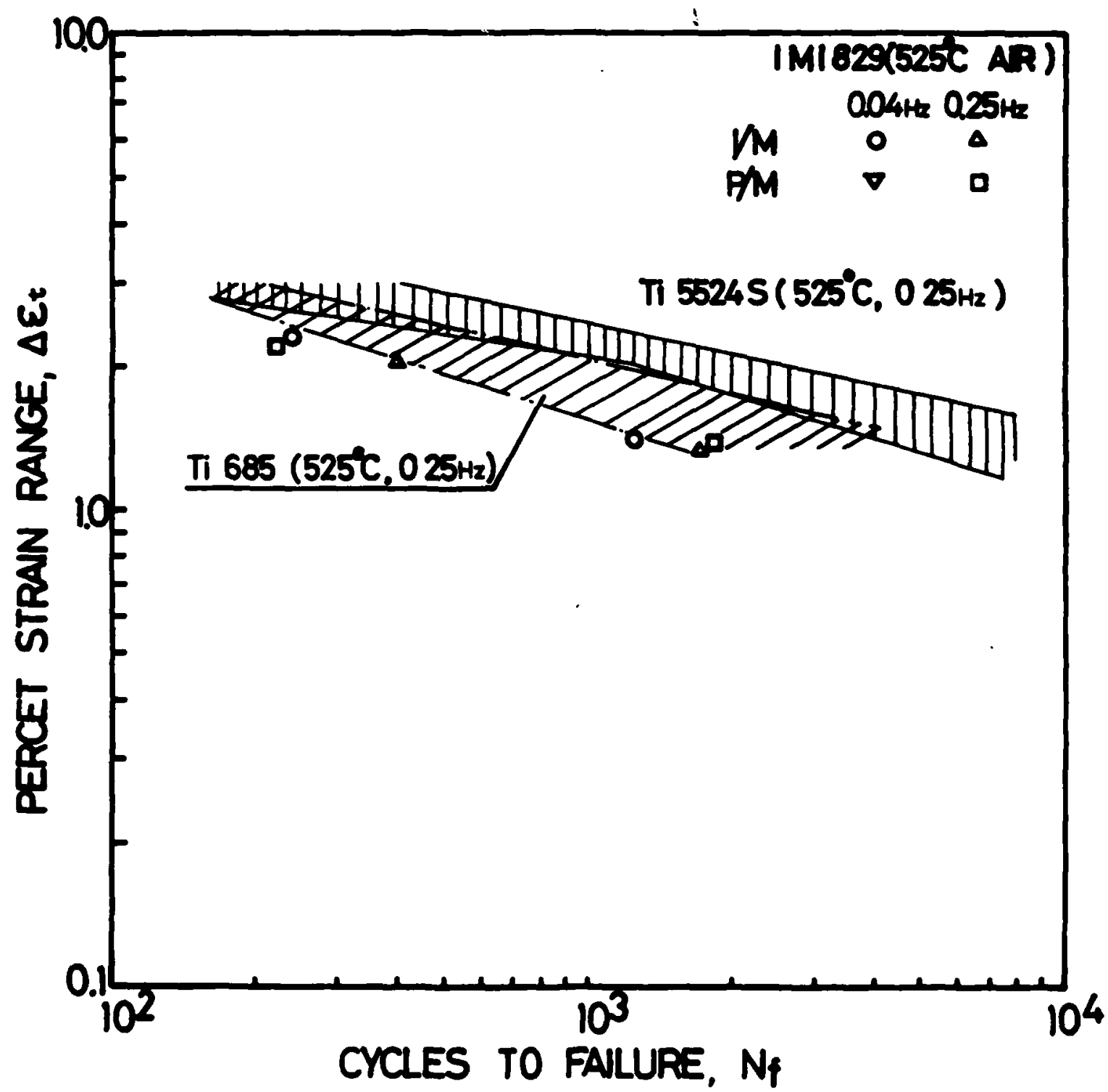

Fig. 27. Comparison of Low Cycle Fatigue behavior of I/M and P/M IMI 829 as a function of total strain range with two other high temperature titanium alloys. 


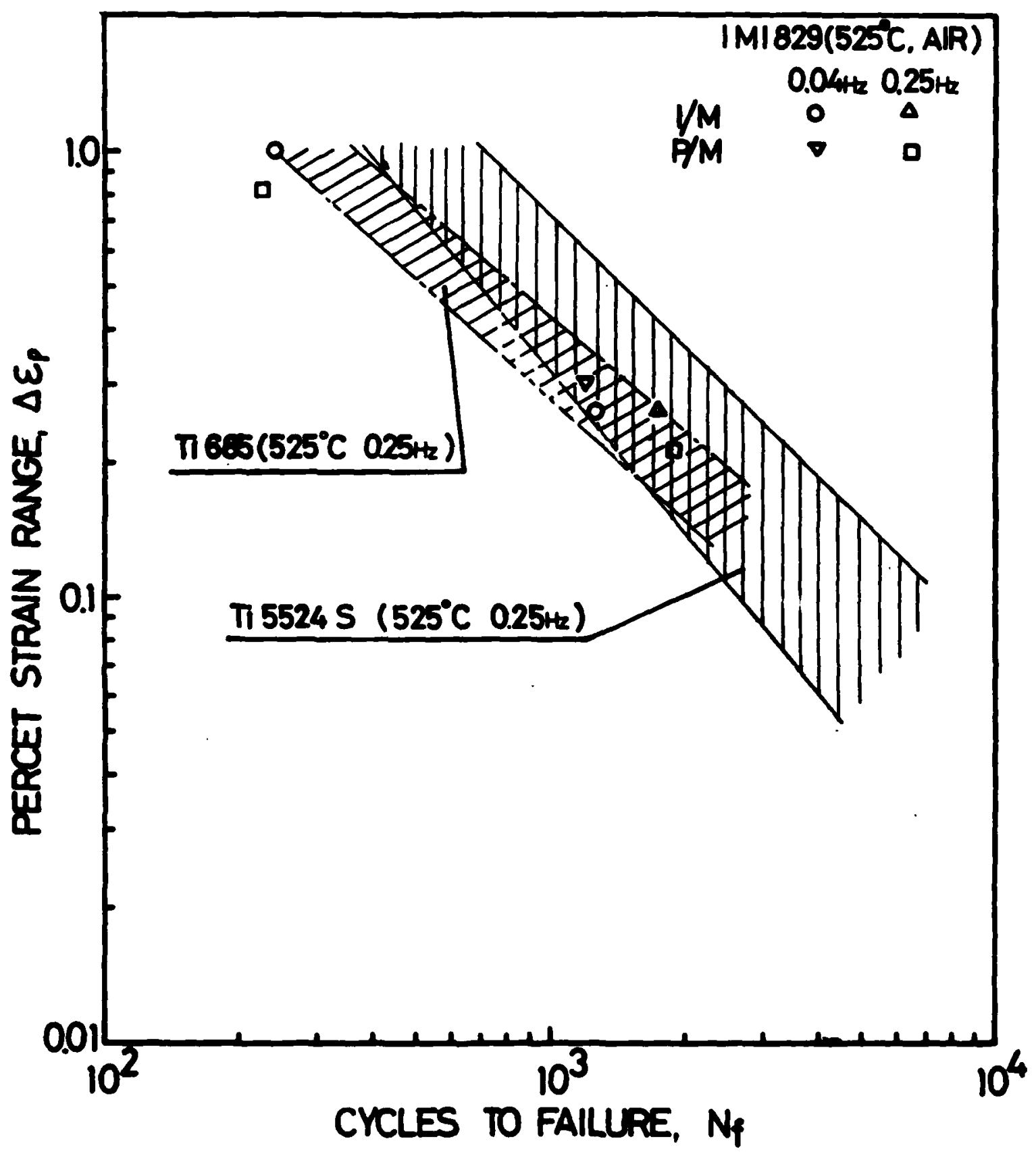

Fig. 28. Comparison of IMI $829 P / M$ and I/M alloys with two other high temperature titanium alioys as a fraction of the plastic strain range. 
closure has been termed "roughness-induced", and is conceptually quite different from the continuum type of residual stretch originally considered.

An important consideration with respect to the influence of closure on the threshold level is the distance over which the closure event occurs. Since there is a history effect associated in a decreasing $K$ test, one must be concerned with the possible contribution to closure and the threshold level of material in the wake of a crack that had been stretched at higher $K$ levels. One can remove the influence of any such material by carefully cutting away material in the wake of the crack to within one millimeter of the crack tip. The results of experiments along these lines are indicated in Figs. 29 and 30 . It is seen that removal of the materlal has a small effect on both the closure level and on the subsequent threshold level. A major conclusion drawn is that in a properly conducted decreasing $K$ test much of the closure that affects the closure level occurs within one millimeter of the crack tip in this material. Closure occurring at longer distances has only a minor effect on the threshold level.

Closure development over distances less than one millimeter can be quite important in understanding the behavior of cracks emanating from notches. A key feature of such crack growth is the recognition that when the crack is first formed there is no closure and the crack tip is free to open and close over the full $K$ range. However as the crack advances roughness-induced closure can develop and reduce the effective range of $k$. One can easily see that this process could readily lead to the non-propagation of cracks, for example. Acditionally, as closure develops we may find that the rate of growth of a propagating crack decreases, the so-called anomolous crack growth. To deal with such topics in a quantitative manner 


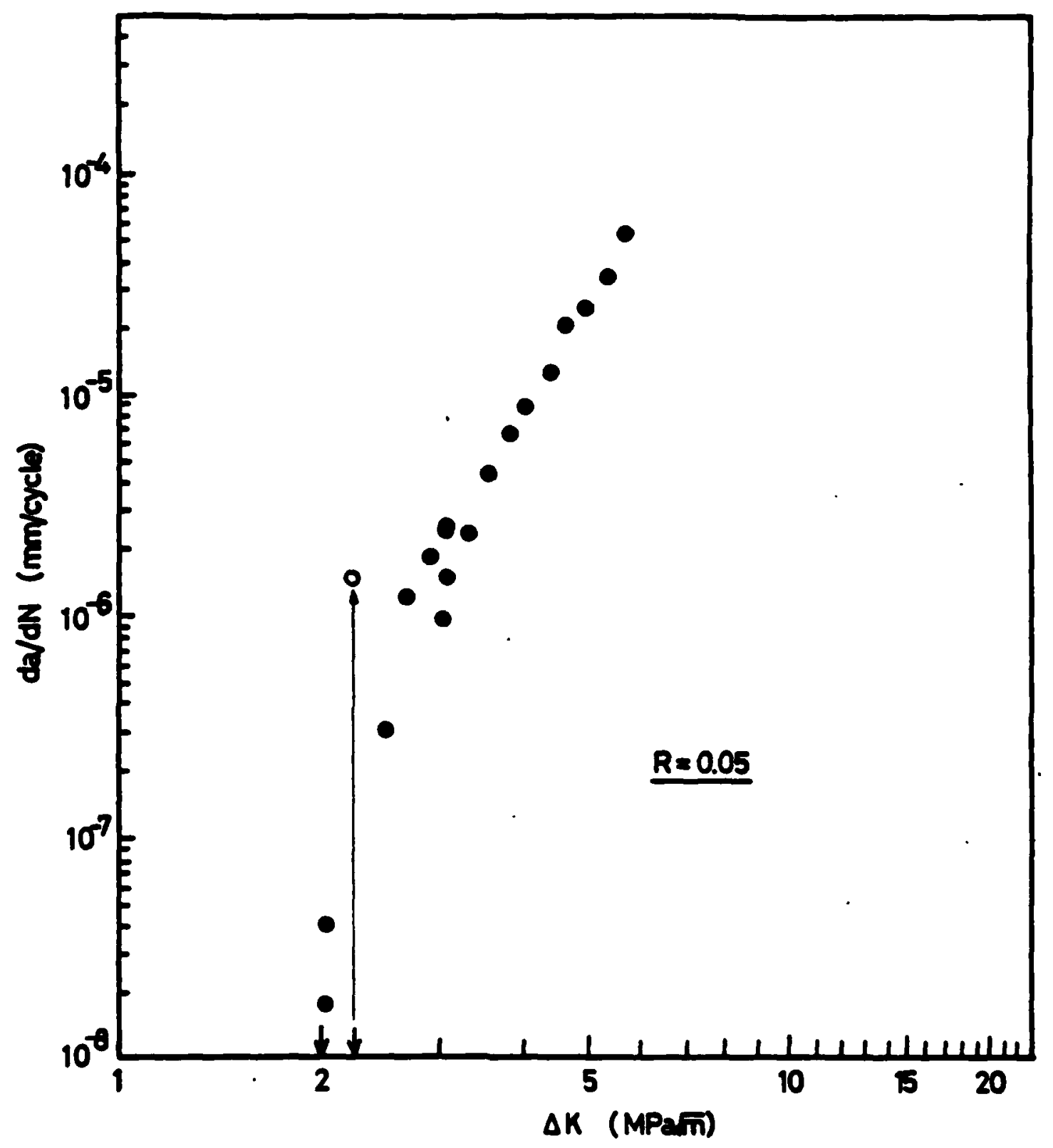

F1g. 29. Results of the near-threshold fatigue crack growth test for X7090 aluminum alloy. Note that the difference between the two thresholds is only $0.2 \mathrm{MPa}$. 


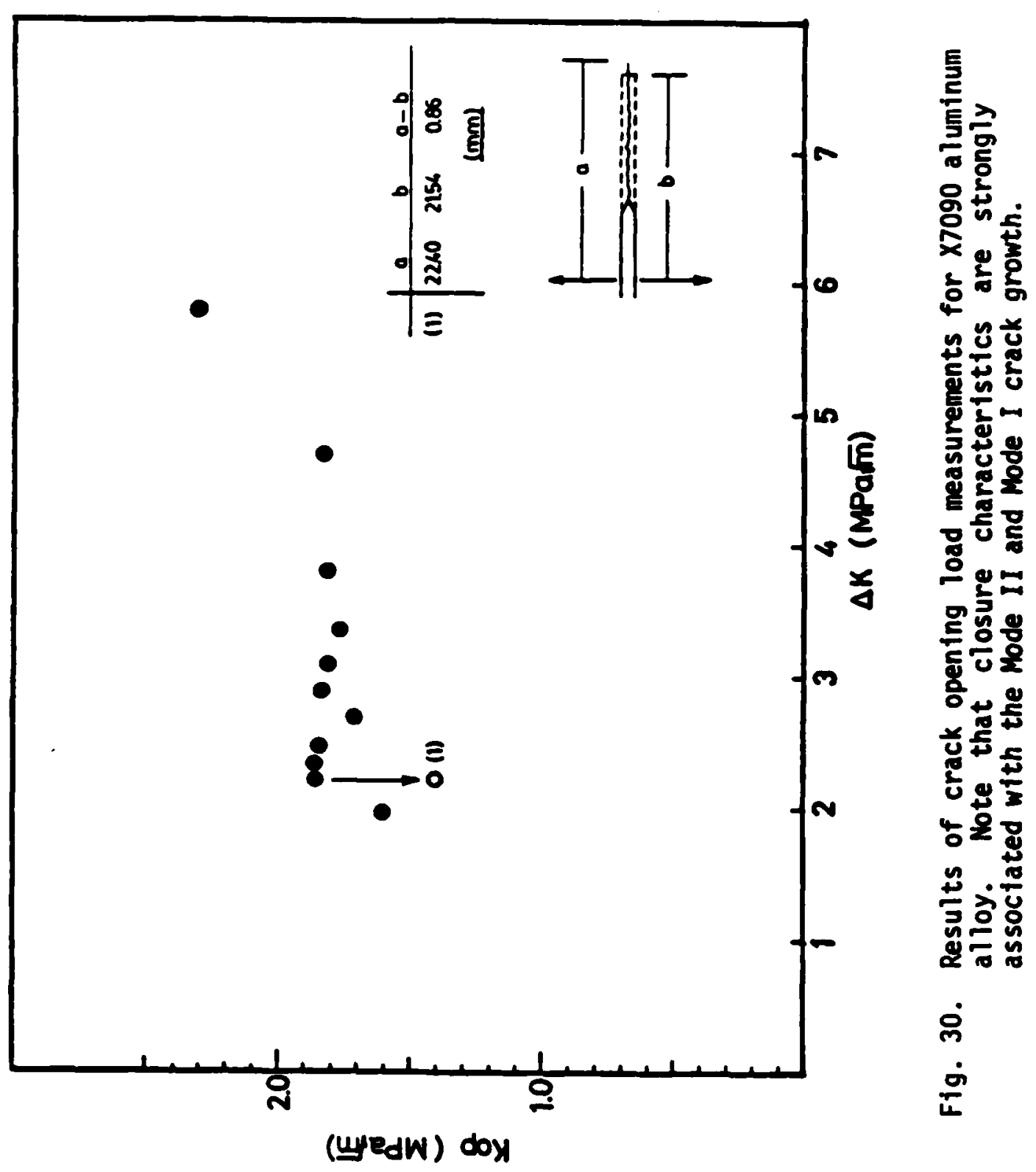


we have developed a quantitative approach which depends upon the rate at which closure develops in the wake of a crack.

Based upon published results on the behavior of cracks emanating from notches we have deduced the Kop level varies as indicated in Fig. 31 . In a distance of half a millimeter the closure level has risen from zero to the value associated with a macroscopic crack for this particuiar material. It is noted that we have recently carried out an experiment the results of which closely simulate the closure development with crack advance depicted in Fig. 31. We make sure of this information in the following way. Fig. 32 is a plot of $\Delta K V \Delta \sigma$ vs. 1 for a crack of length 1 emanating from a hole of radius $c$ based on three methods of calculation. Curve $A$ represents the exact solution for a crack emanating from a hole. Curve B is the solution if the crack is taken to be equal to the actual length plus the radius of the hole. For large crack sizes these curves merge. Curve $C$ is the assumed variation used in the proposed model. To account for the fact that the initial crack is in a plastic zone large with respect to the crack length the initial value of $\Delta K / \Delta \sigma$ is increased from curve $A$ to that of curve $B$. Then as crack closure develops in accord with Fig. 31 the value of $\Delta \mathrm{Keff} / \Delta \sigma$ follows curve $C$. Because of the dip in curve $C$ it is necessary that in order to keep a crack propagating at a given rate that the stress range be increased to maintain a constant value of $\Delta$ Keff. This is indicated in Fig. 33 which compares predictions, curves $C, D$, and $E$ with published experimental results. Curve $C$, for example, begins on the line $B$ which represents the threshold condition in the absence of closure. As closure develops the stress requires for propagation increases to a maximum before decreasing as the crack increases in length. In order for a crack to propagate this maximum must be exceeded. The experimental data is in accord with this view. Arrested cracks form below this maximum and propa- 

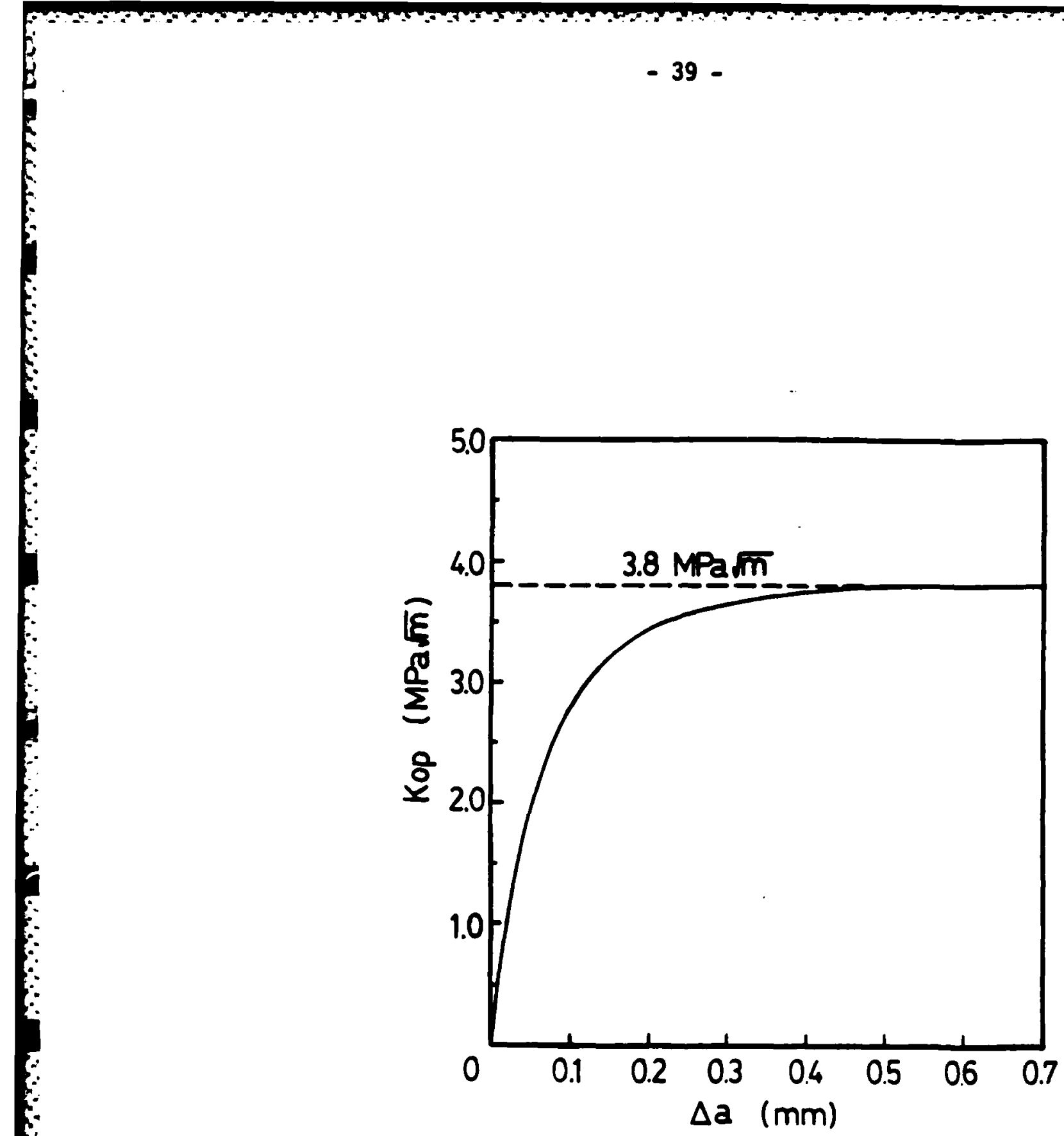

Fig. 31. Assumed development of closure as a short crack extends from zero length to a length of $0.5 \mathrm{~mm}$. 


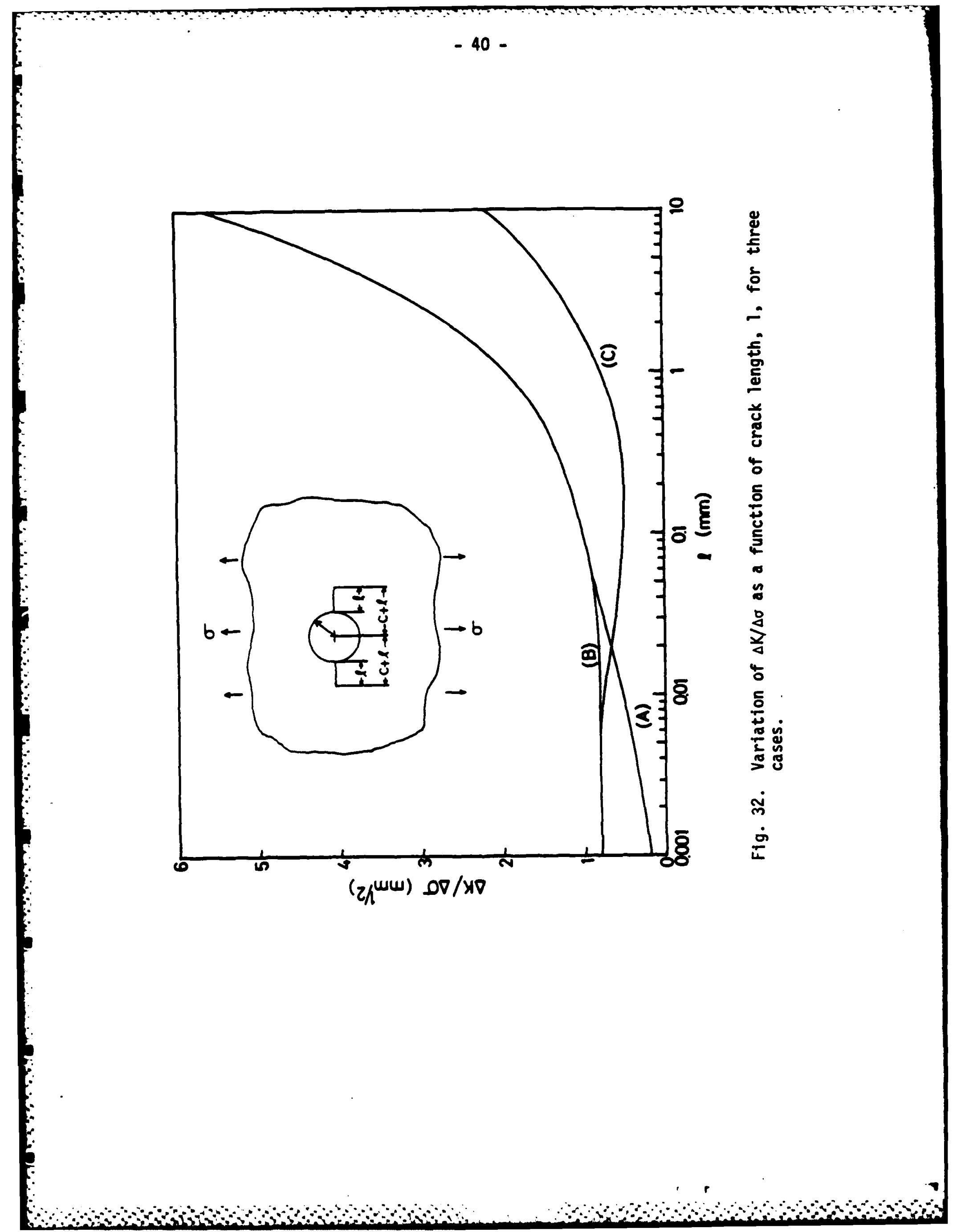




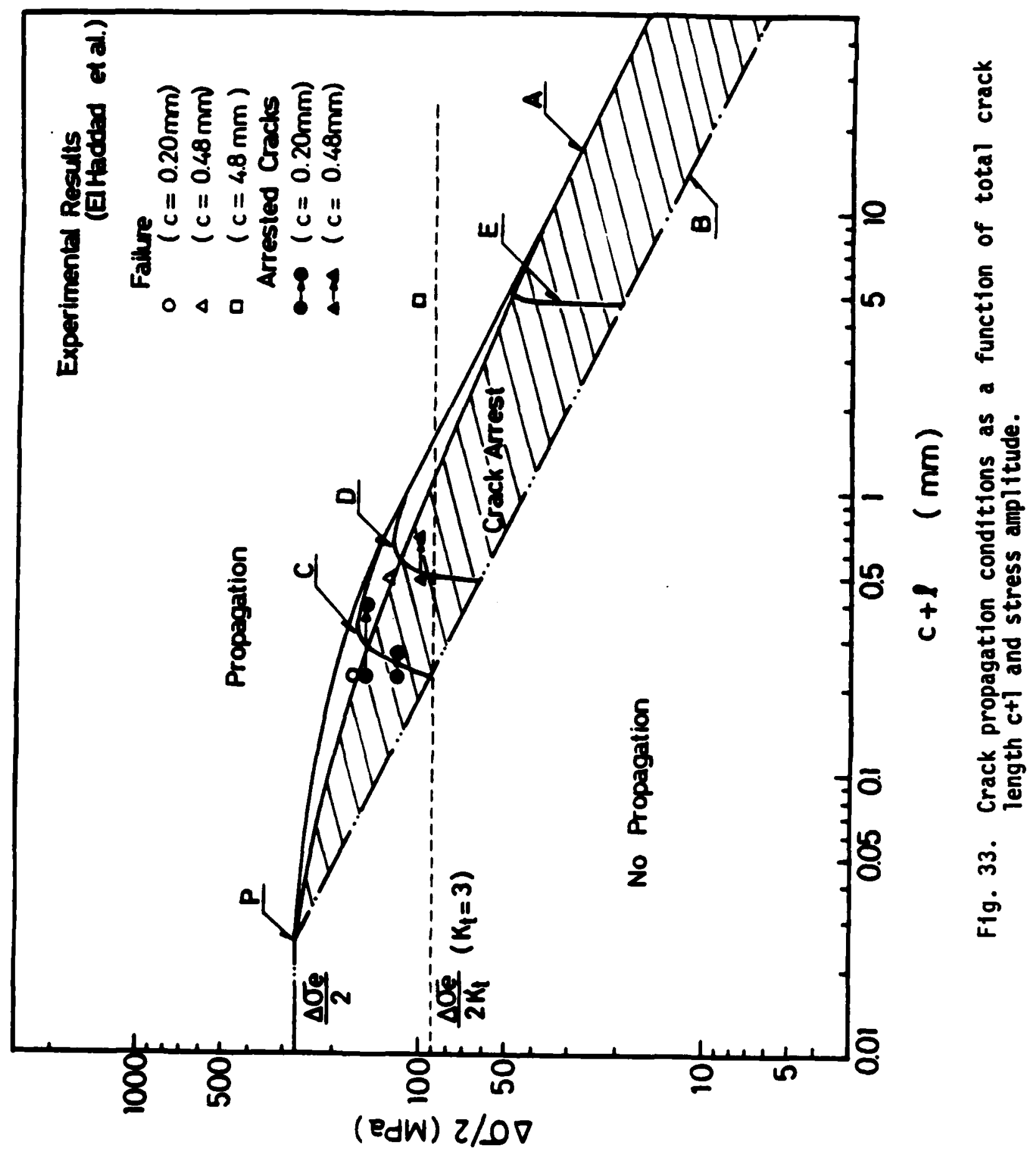


gating cracks form above. Note also that as the radius of the hole is increased that the stress maximum decreases. This fact leads to a direct understanding of the cause underlying the fatigue notch effect, i.e., that for a given stress intensity factor a small radius is not as severe in reducing fatigue strength as a large radius. This point is emphasized in Fig. 34 which compares predictions based on Fig. 33 with empirical relations found in the literature.

Fig. 35 indicates the regimes on the da/dN vs. $\Delta K$ plot wherein the above approach based on crack closure considerations can be applied. Closure as employed in the analysis is a continuum consideration, and as such can only be applied in the region to the right of the cross-hatched area. Nevertheless it can account for various types of crack growth below the threshold for long cracks as indicated by the curves labeled A, B and C. A micromechanics approach involving dislocation behavior within individual grains may be needed to deal with situations within the cross-hatched region. The precise position on the lower bound for the continuum approach will depend on the material. For materials in which the endurance limit is a propagation rather than an initiation 1 imit it may be possible to extend the approach to very small crack sizes as indicated in Fig. 36 to account for the R-dependency of the endurance 1 imit in the same way that the R-dependency of the threshold level has been treated. We also need to know more about the development of closure in different materials as a function of R-ratio as indicated in Fig. 37.

The proposed method of analysis also has certain implications for design as indicated in Fig. 38. In selecting a material for a given application it may seem appropriate to select a material of high tensile strength because of a higher smooth bar fatigue 1 imit. However in the presence of a flaw or crack the threshold for fatigue crack growth may be less in the 


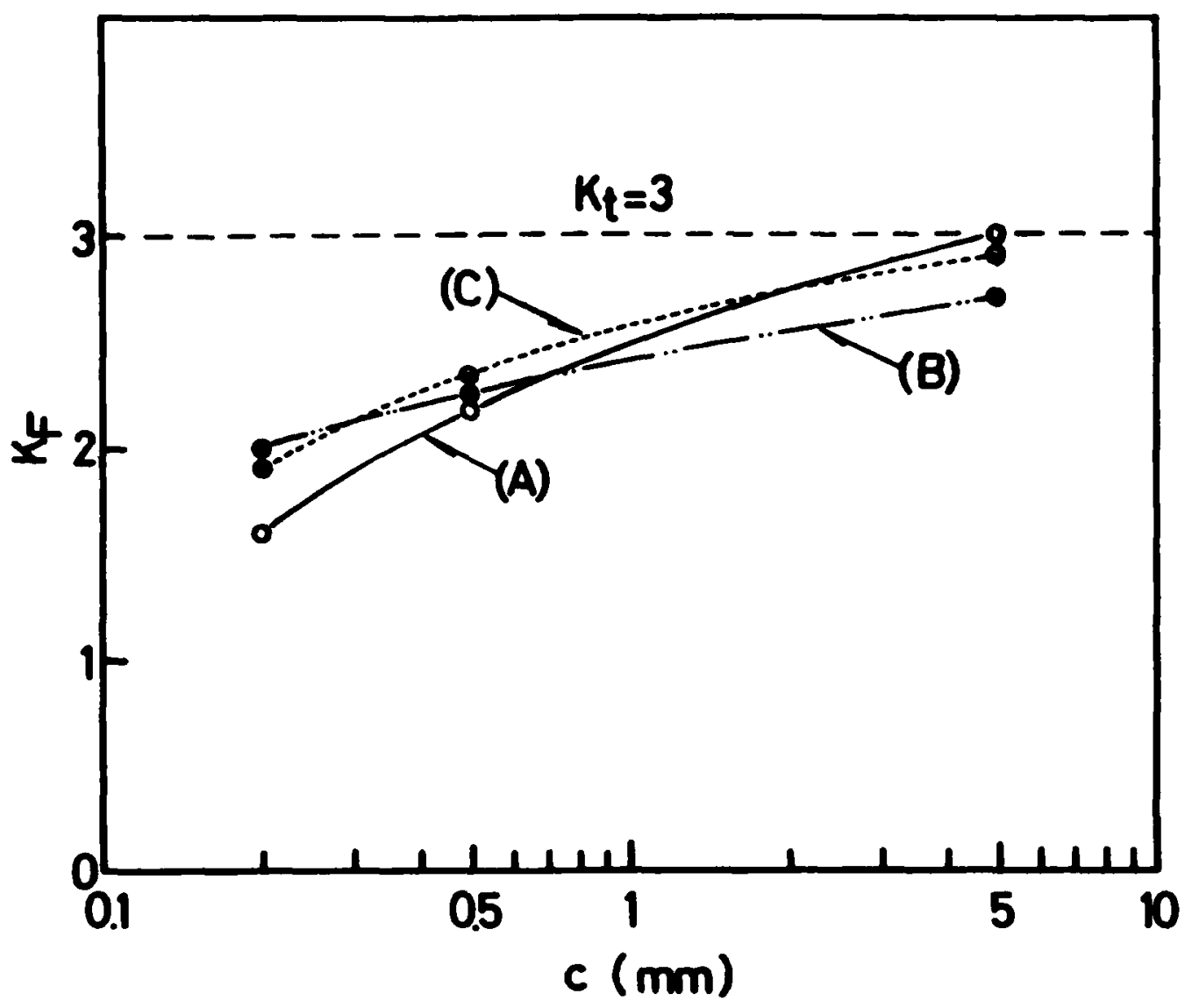

Fig. 34. Variation of $K_{F}$ as a function of hole radius for three cases;

(A) based on the present analysis;

(B) based on $K_{F}=1+\frac{K_{T-1}(5)(6)}{1+\sqrt{\rho} / \rho},\left(\rho^{\prime}=0.4 \mathrm{~mm}\right)$;

(c) based on $K_{F}=1+\frac{K_{T-1}(7)}{1+\frac{a_{0}}{\rho}}\left(a_{0}=0.25 \mathrm{~mm}\right)$. 


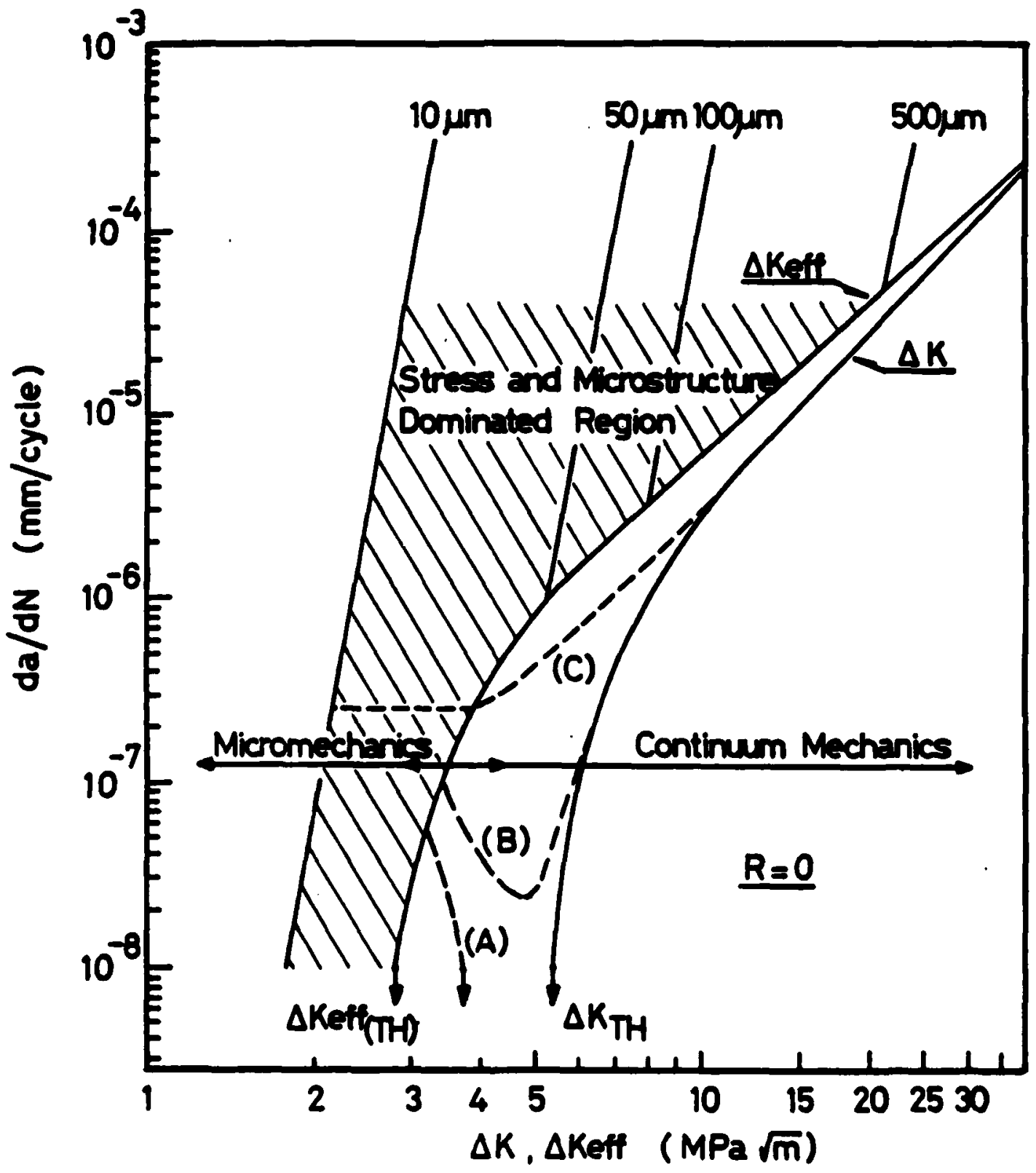

Fig. 35. Rate of fatigue crack growth in modified $9 \mathrm{Cr}$-iMo steel. Regions of applicabllity of micromechanics and continuum mechanics are indicated. Microcrack sizes are indicated. Curves (A), (B) and (C) indicate anomalous crack growth behavior during development of closure including nonpropagating crack (A). 


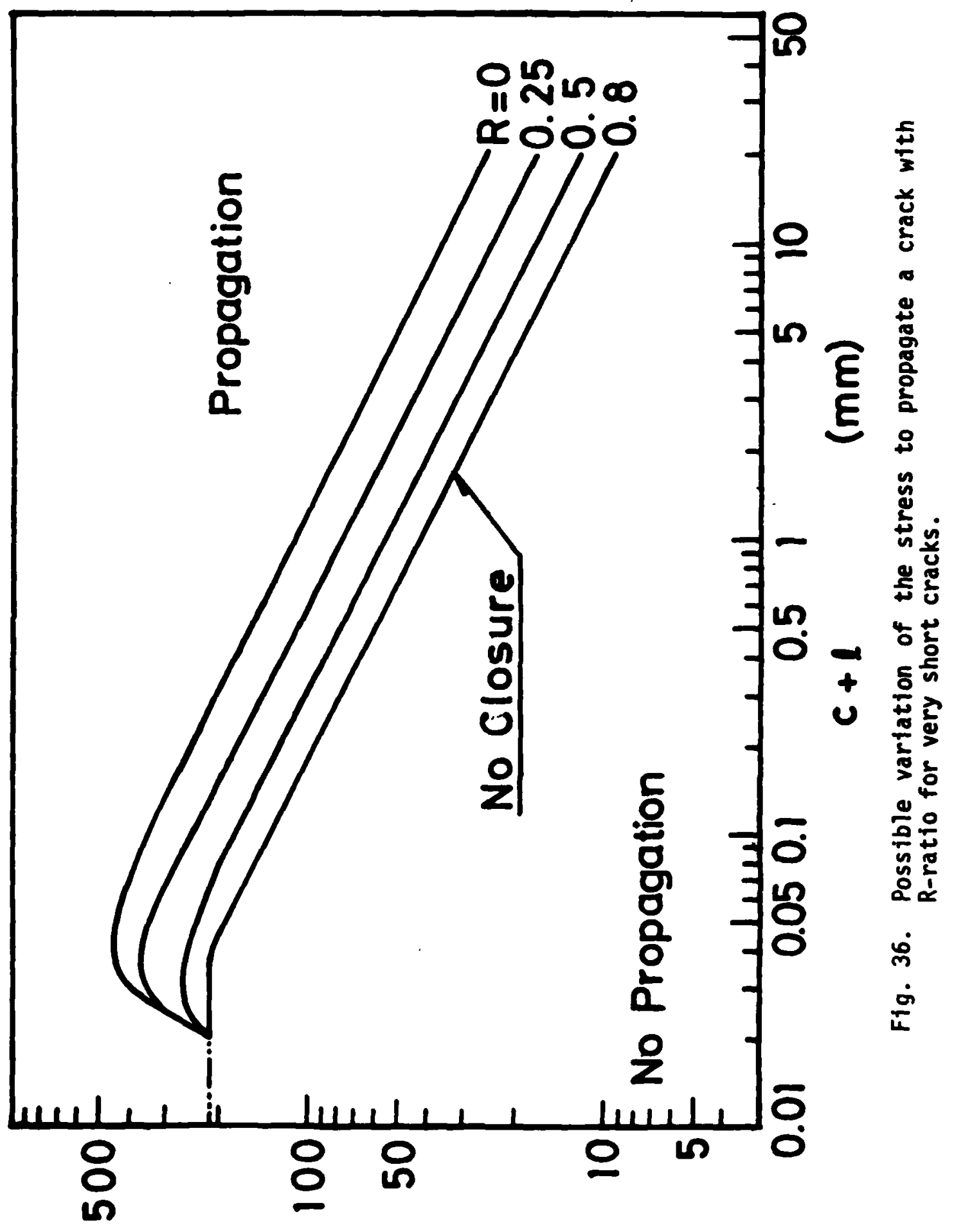

(edW) $\quad \nabla \nabla$ 


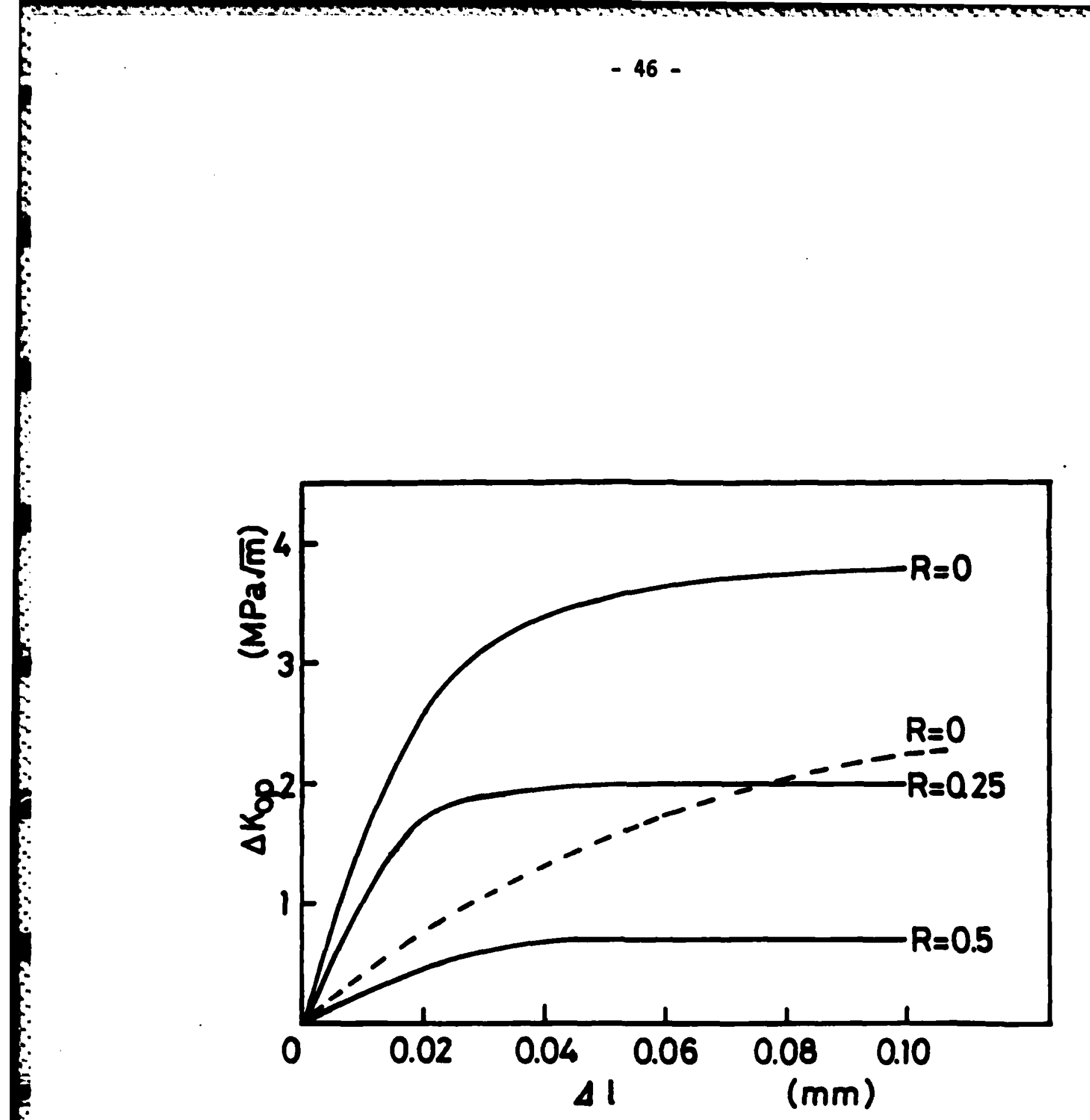

Fig. 37. Possible variation in closure development as a function of $R$ for two different materials. 
case of a high strength steel as compared to one of lower strength. This lower threshold results from less closure. The result is that in the presence of a flaw the material of lower strength may actually be more fatigue resistant than the higher strength material.

Consideration of closure also leads to a better understanding of factors influencing crack growth under variable amplitude loading, and in particular the cause for retardation of the crack growth rate when the overloads are applied. Fig. 39 is an example of this retardation. Note that the growth rate immediately after the application of the overload is slightly higher than prior to the overload but as the crack advances the growth rate decreases, a phenomenon known as delayed retardation. Finally the crack accelerates and returns to the normal level once it is out of the zone of influence of the overload event. From our previous work we know that the retardation is due to closure in the surface or plane stress region, and this is supported by the results shown in Fig. 40 . The delay phenomenon can be understood by considering the residual stresses in the plastic zone ahead of the crack following the overload. They are compressive and so when the crack advances into the plastic zone and relaxes this compressive stress the relaxed material will expand and contribute to closure. The maximum relaxation will occur when the crack tip is at the center of the zone, the position at which the growth rate is a minimum. This situation and related calculations is depicted in Fig. 41 and compared with experimental results in $\mathrm{Fig} .42$.

A natural extension of the approach would be to spectrum loading. Preliminary testing has been carried out in our laboratory using the Minitwist program representative of the loads experienced by the wing structure of transport aircraft. The results of these tests are shown in Fig. 43. 


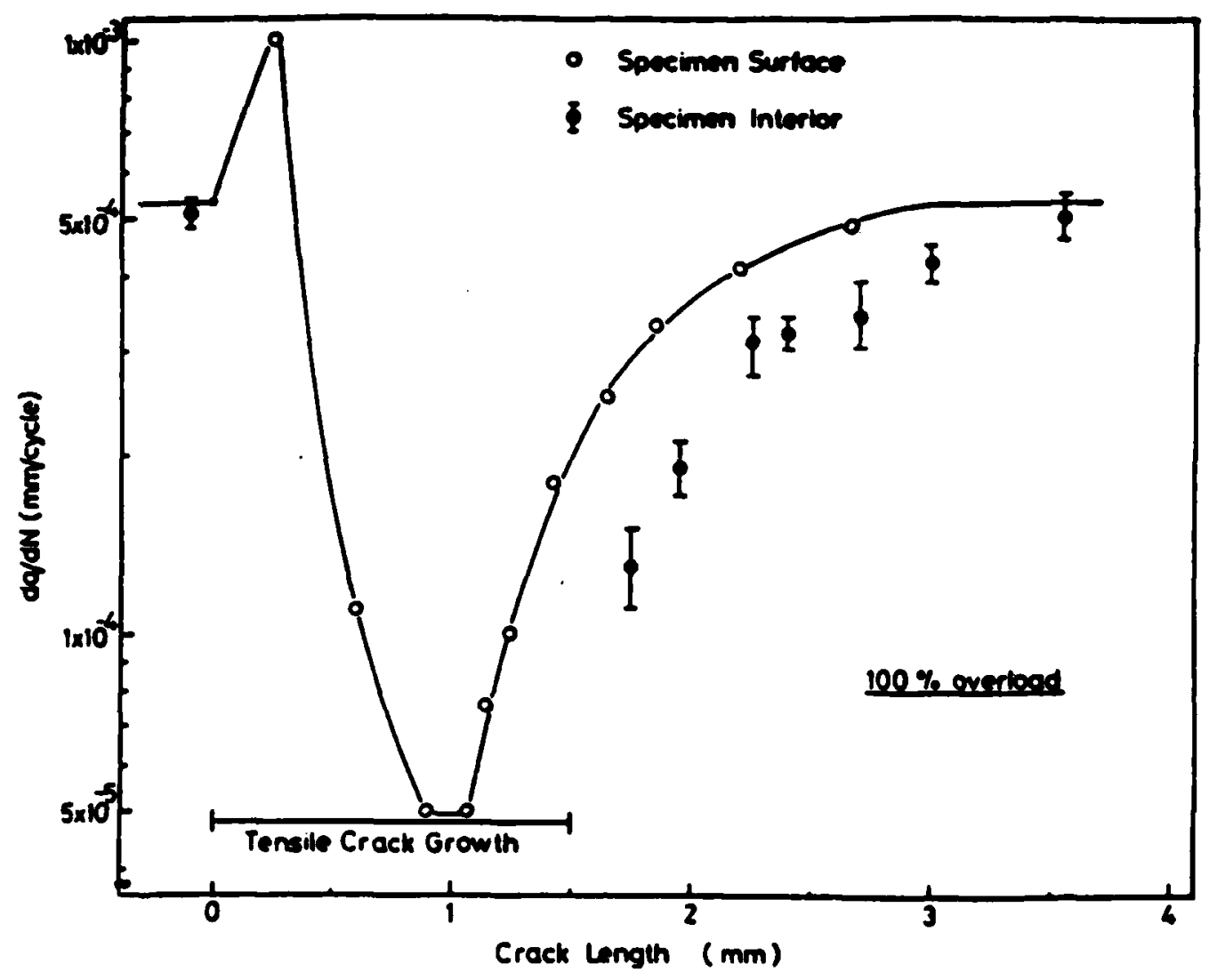

Fig. 39. Crack growth rate after an overload. 2219-T87 I/M alloy.

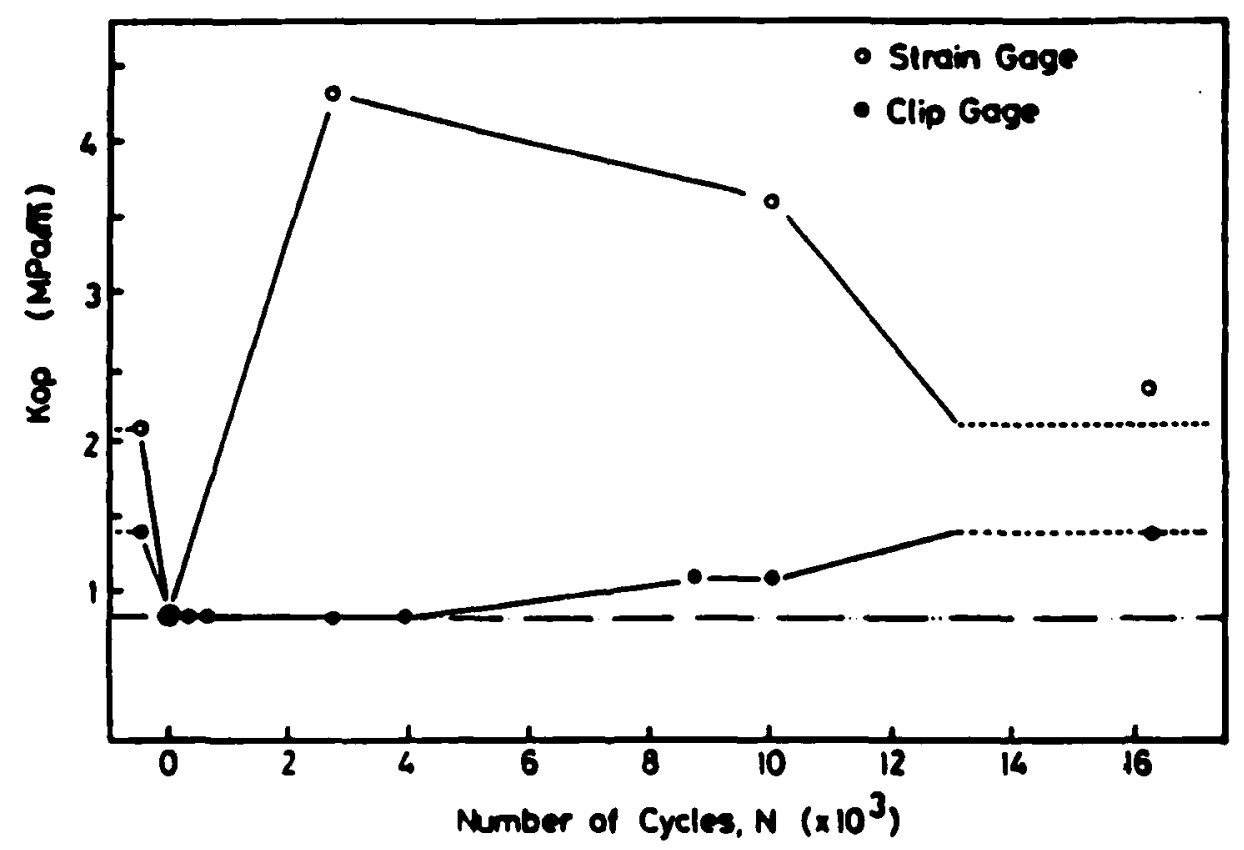

Fig. 40. Crack closure behavior after an overload. Strain gage measures surface closure. Clip gauge measures through thickness closure. 2219-T87 1/M alloy. 


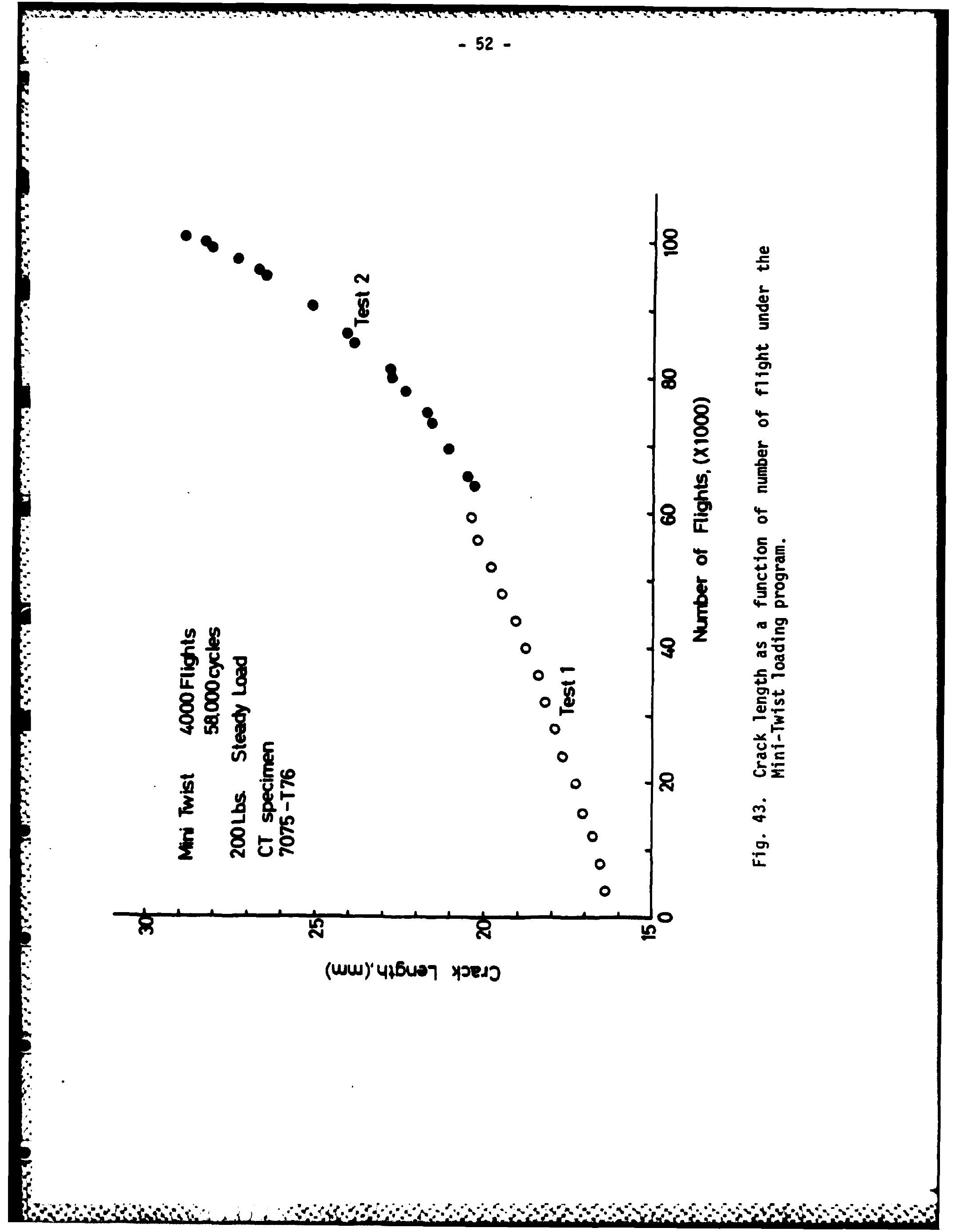




\section{CONCLUSIONS}

1. A comparison of the fatigue crack growth behavior of high strength $P / M$ and $I / M$ aluminum alloys leads to the following conclusions.

a. In the near threshold region $P / M$ and $1 / M$ alloys are comparable in their resistance to fatigue crack growth.

b. In the intermediate region the $1 / M$ alloy showed a lower fatigue crack growth rate at a given $\Delta K$ level. This reduction is associated with a higher level of crack closure in the $1 / M$ alloy.

c. In the terminal region the $1 / M$ alloy exhibited a lower crack growth rate because of the higher toughness. In this compariston the yield and tensile strengths were higher in the $P / M$ alloys and this may account for the lower toughness of these materials. At comparable strength levels there may be no difference in fracture toughness and the crack growth rates may be closer together in the terminal region.

d. No defect which might reduce the resistance to fatigue crack growth was observed in any of the $P / M$ alloys. The fatigue resistance of unnotched $P / M$ alloy specimens was greater than that of the $1 / M$ alloy which also indicates that no significant defects were present in the $P / M$ alloys.

e. Grain size is an important characteristic affecting the threshoid level. $P / M$ and $1 / M$ alloys with grain sizes in the range of 5-10 $\mu \mathrm{m}$ exhibit more closure and have higher thresholds for $R=0.05$ loading as compared to a P/M alloy whose grain size was less than IH.

2. Crack closure behavior has been found to be responsible for the anomalous behaviour of short cracks $(<50 \mu)$ emanating from notches. A method of analys is has been formulated based on the rate and magnitude of develop- 
ment of closure in the crack of a newly formed fatigue crack. This analysis not only accounts for short crack behavior but also related topics such as the non-propagation of cracks, the notch size-effect in fatigue, and fatigue notch sensitivity. 


\section{Papers published}

(1) K. Minakawa and A. J. McEvily, "On Crack Closure in the Near-Threshold Region", Scripta Metallurgica, Vol. 15, p. 633, 1981.

(2) K. Minakawa and A. M. McEvily, "On Near-Threshold Fatigue Crack Growth in Steels and Aluminum Alloys", in "Fatigue Thresholds", Proc. of Int1. Symposium, Stockholm, Vo1. 1, p. 373, 1981, EMAS.

(3) A. J. McEvily and K. Minakawa, "Recent Development in Fatigue Crack Growth", in "Fracture Tolerance Evaluation", Proc. of the U.S.-JAPAN Seminar, Honolulu, p. 139, 1982, Toyoprint.

(4) A. J. McEvily and K. Minakawa, "Fatigue Crack Growth in the NearThreshold Region", in "ICSMA Strength of Metals and Alloys", Proc. of Int1. Conf., Melbourne, Vo1. 2, p. 845, 1982, Pergamon Press.

(5) A. J. McEvily, "On the Quantitative Analysis of Fatigue Crack Propagation" ASTM STP 811, p. 283, 1983, American Society for Testing and Materials.

(6) K. Minakawa, J. C. Newman, Jr. and A. J. McEvily, "A Critical Study of the Crack Closure Effect on Near-Threshold Fatigue Crack Growth", Fatigue of Engng. Mater. and Struct., Vol. 6, No. 4, p. 359, 1983.

(7) A. J. McEvily and K. Minakawa, "On the Role of Crack Closure in Fatigue Crack Growth", in Proc. of ICF Sympostum on Fracture Mechanics", Beijing, p. 763, 1983, Science Press, Beijing, China.

(8) A. J. McEvily and K. Minakawa, "Crack Closure and the Growth of Short and Long Fatigue Cracks", Scripta Metallurgica, Vol. 18, No. 1, p. 71,1984 .

(9) A. J. McEvily and K. Minakawa, "Crack Closure and the Conditions for Fatigue Crack Propagation", in "Fatigue Crack Growth Threshold Concepts", Proc. of Intl. Sympostum Philadelphia, p. 517, 1984, AIME. 
(10) A. J. McEvily and K. Minakawa, "On the significances of the Threshold for Fatigue Crack Growth", in "Advances in Fracture Research", Proc. of ICF6, New Dehli, Vo1. 3, p. 1641, 1984, Pergamon Press.

(11) A. J. McEvily, K. Minakawa and H. Nakamura, in "Fracture Mechanics, Microstructure and the Growth of Short and Long Fatigue Cracks", in "Fracture: Interactions of Microstructure, Mechanisms, Mechanics", Proc. of Symposium, Los Angeles, p. 215, 1984, AIME.

(12) S. Z. Liu, K. Minakawa, B. Scholtes and A. J. McEvily, "The Effect of Cold Rolling on the Fatigue Properties of Ti-6Al-4V", Metallurgical Transactions, A., Vol. 16A, p. 144, 1985.

\section{Papers Submitted}

(1) A. J. McEVily, "Fracture Prevention in the Motor Vehicle Industries", to be published in "Fracture Prevention in Energy and Transport Systems", Proc. of Intl. Conf., Rio de Janeiro, November, 1983, EMAS.

(2) K. Minakawa, G. Levan and A. J. McEvily, "The Influence of Load Ratio on Fatigue Crack Growth Rates in 7090-T6 and IN9021-T4 Aluminum Alloys, submitted to Metallurgical Transactions A.

(3) A. J. McEvily and K. Minakawa, "Crack Closure and Fatigue Crack Growth under Variable Amplitude Loading", submitted to ASTM Special Technical Publication.

\section{Presentations}

(1) K. Minakawa and A. J. McEvily, "On Near-Threshold Fatigue Crack Growth in Steels and Aluminum Alloys", the Intl. Symposium on Fatigue Thresholds, Stockholm, June 1981. 
(2) A. J. McEvily and K. Minakawa, "Recent Developments in Fatigue Crack Growth", the U. S.-Japan Joint Seminar "Fracture Tolerance Evaluation", Honolulu, December, 1981.

(3) A. J. McEvily, "Fatigue Crack Propagation" seminar at Inco Research and Development Center, Suffern, March, 1982.

(4) K. Minakawa, J. A. Ruppen and A. J. McEvily, "On Fatigue Crack Growth in Aluminum and Titanium Alloys in the Near-Threshold Region", ASTM Symposium "Fractography in Failure Analys is of Ceramics and Metals", Philadelphia, April, 1982.

(5) A. J. McEVily, "On the Quantitative Analysis of Fatigue Crack Propagation" Intl. Conf. on Quantitative Measurement of Fatigue Damage, Dearborn, May, 1982.

(6) A. J. McEvily, "Fatigue Crack Propagation", seminar at NASA Langley Research Center, Hampton, June, 1982.

(7) A. J. McEvily and K. Minakawa, "Fatigue Crack Growth in the NearThreshold Region", 6th Intl. Conf. on the Strength of Metals and Alloys, Melbourne, August, 1982.

(8) S. Z. Liu and A. J. McEvily, "Effect of Variable Amplitude Loading on the Fatigue Life of Titanium", TMS-AIME Fall Meeting, St. Louis, October, 1982.

(9) A. J. McEvily, "Fatigue Crack Propagation", ASM Rhode Island Chapter Meeting, Providence, November 1982.

(10) K. Minakawa and A. J. McEvily, "Near-Threshold Fatigue Crack Growth in Aluminum Alloys in Alr and 3.5 pct NaCl Solution, TMS-AIME 112th Annual Meeting, Atlanta, March, 1983.

(11) A. J. McEvily and K. Minakawa, "Crack Closure and the Conditions for Fatigue Crack Propagation, Intl. Symposium on Fatigue Crack Growth Threshold Concepts, Philadelphia, October, 1983. 
$-58-$

(12) A. J. McEvily, "Fracture Prevention in the Motor Vehicles Industries", Int 1. Conf. on Fracture Prevention in Energy and Transport Systems, Rio de Janeiro, November, 1983.

(13) A. J. McEvily, K. Minakawa and H. Nakamura, "Fracture Mechanics, Microstructure and the Growth of Short and Long Fatigue Cracks" Symposium on Synergism of Microstructure, Mechanisms and Mechanics in Fracture, 113th AIME Annual Meeting, Los Angeles, February, 1984.

(14) A. J. McEvily and K. Minakawa, "On the Significance of the Threshold for Fatigue Crack Growth", 6th IntI. Conf. on Fracture, New Delhi, December, 1984. 


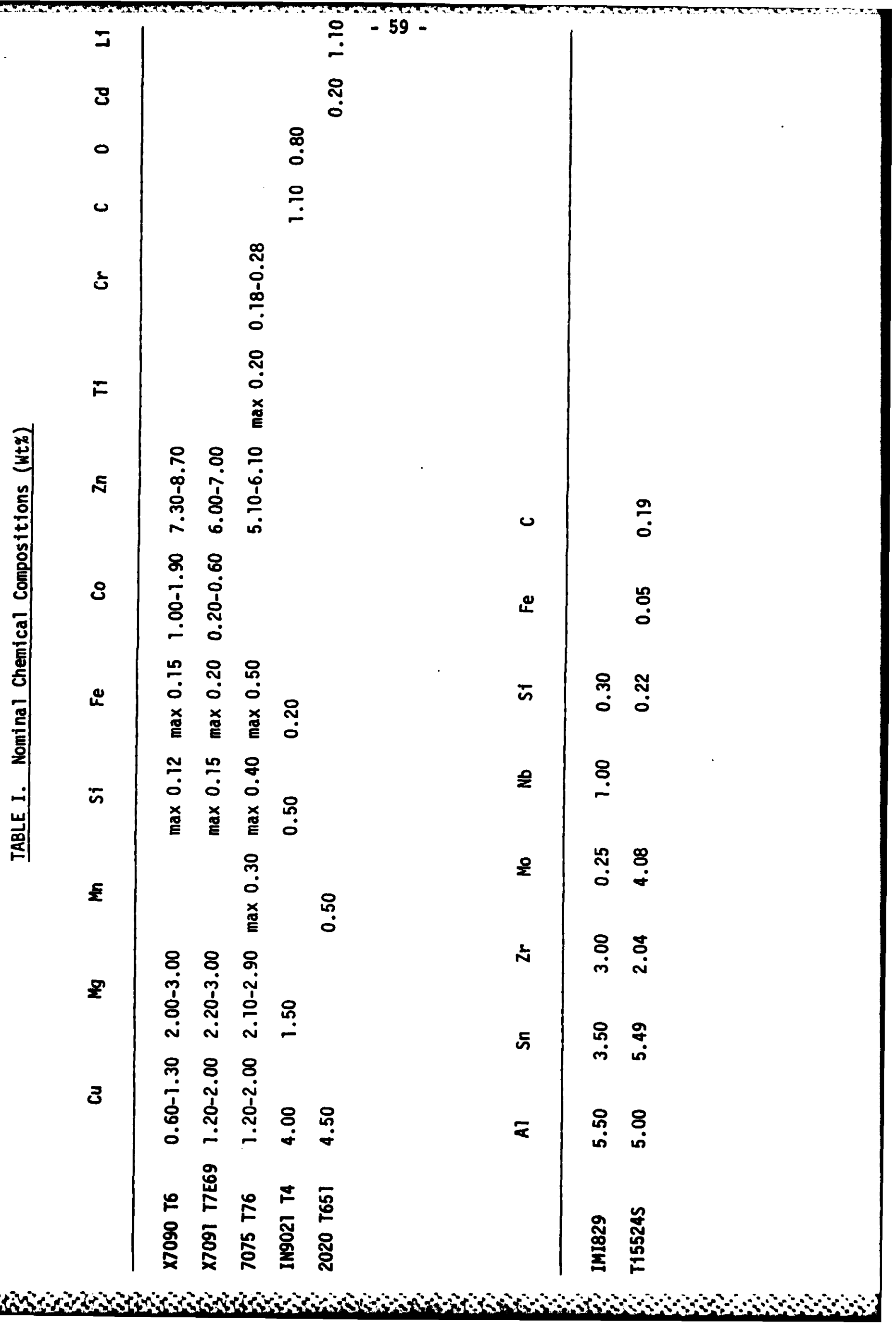




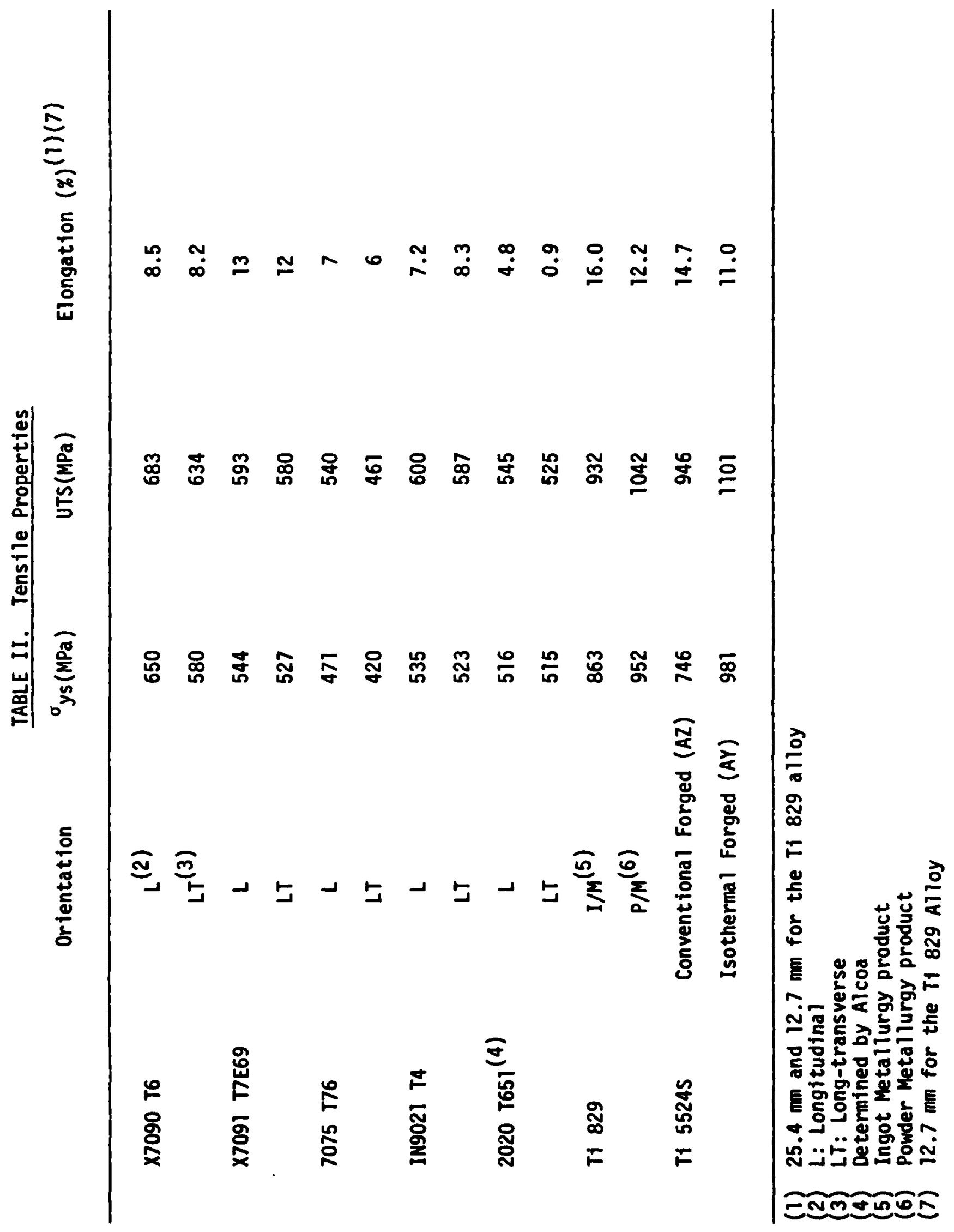




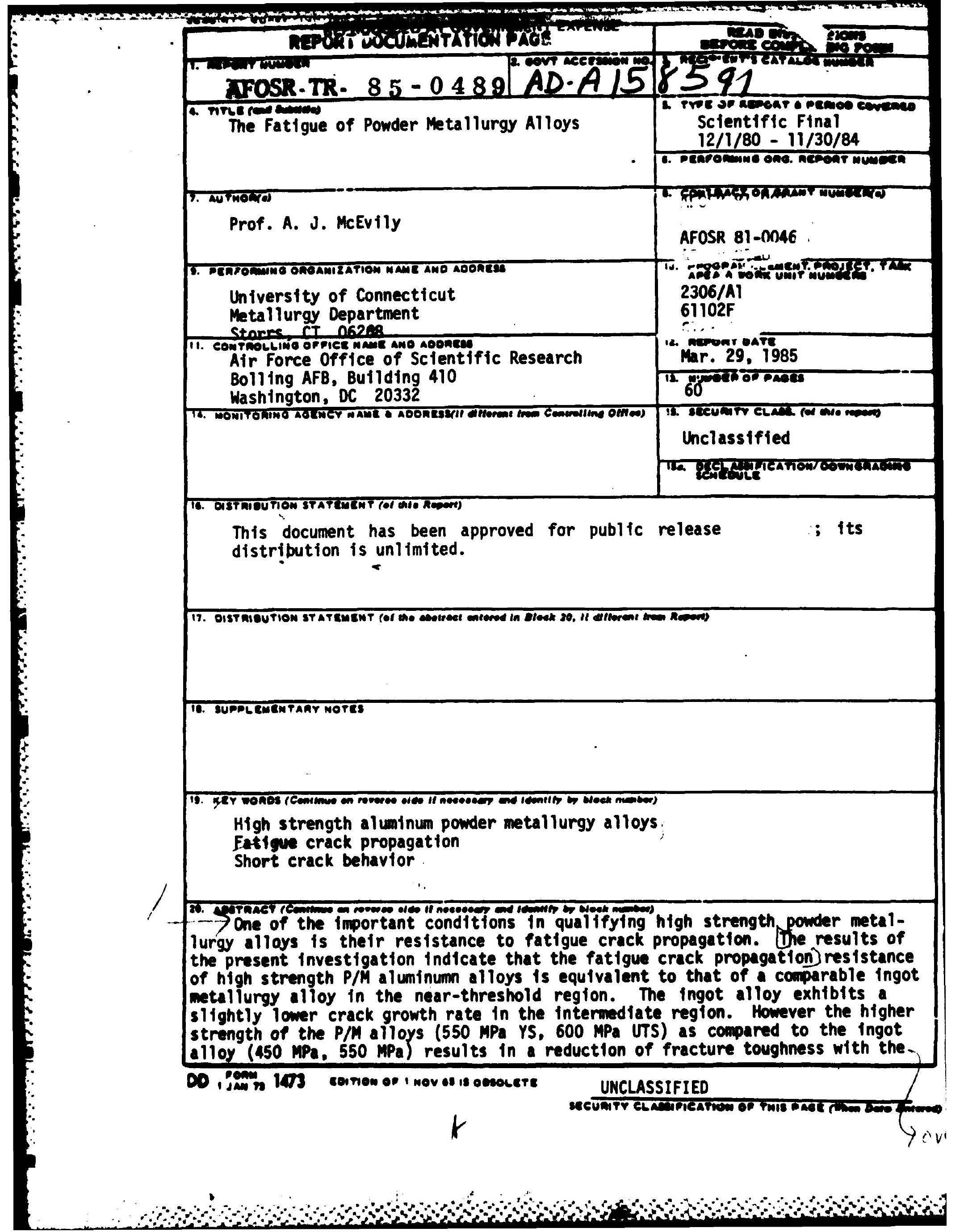


